\title{
Stereoselective formation and hydration of 12-methylbenz $[a]$ anthracene 5,6-epoxide enantiomers by rat liver microsomal enzymes
}

\author{
Shen K. YANG, ${ }^{*} \ddagger$ Mohammad MUSHTAQ, ${ }^{*}$ Henri B. WEEMS, ${ }^{*}$ Dwight W. MILLER $\dagger$ and Peter P. FU $\dagger$ \\ *Department of Pharmacology, F. Edward Hébert School of Medicine, Uniformed Services University of the Health Sciences, \\ Bethesda, MD 20814-4799, U.S.A., and †National Center for Toxicological Research, Food and Drug Administration, Jefferson, \\ AR 72079, U.S.A.
}

\begin{abstract}
The K-region trans-5,6-dihydrodiols formed in the metabolism of 12-methylbenz[a]anthracene (12-MBA) by liver microsomal preparations from untreated, phenobarbital-treated and 3-methylcholanthrene-treated male Sprague-Dawley rats were found by chiral stationary-phase h.p.l.c. (c.s.p.-h.p.l.c.) analyses to contain $(5 S, 6 S) /(5 R, 6 R)$ enantiomer ratios of $93: 7,88: 12$ and $97: 3$ respectively. The absolute stereochemistry of a 12-MBA trans-5,6-dihydrodiol enantiomer was elucidated by the exciton-chirality c.d. method. The 5,6-epoxides formed in the metabolism of 12-MBA by liver microsomal preparations from untreated, phenobarbital-treated and 3-methylcholanthrene-treated male Sprague-Dawley rats in the presence of the epoxide hydrolase inhibitor 3,3,3-trichloropropylene 1,2-oxide were isolated from a mixture of metabolites by normal-phase h.p.l.c., and their $(5 S, 6 R) /(5 R, 6 S)$ enantiomer ratios were found by c.s.p.-h.p.l.c. analyses to be 73:27, 78:22 and 99:1 respectively. The absolute configurations of 12-MBA 5,6-epoxide enantiomers, resolved by c.s.p.-h.p.l.c., were determined via high-resolution $(500 \mathrm{MHz})$ proton-n.m.r. and c.d. spectral analyses of the two isomeric methoxylation products derived from each of the 12-MBA 5,6-epoxide enantiomers. Enantiomeric pairs of the two methoxylation products were resolved by c.s.p.-h.p.l.c. The results indicate that enantiomeric $5 S, 6 R$-epoxide and $5 S, 6 S$-dihydrodiol were the major enantiomers preferentially formed in the metabolism at the K-region 5,6-double bond of 12-MBA by all three rat liver microsomal preparations. Optically pure 12 -MBA $5 S, 6 R$-epoxide was hydrated predominantly at the $\mathrm{C}_{(6)}$ position $(R$ centre) to form 12-MBA trans-5,6-dihydrodiol with a $(5 S, 6 S) /(5 R, 6 R)$ enantiomer ratio of $97: 3$. However, optically pure 12-MBA $5 R, 6 S$-epoxide was hydrated nearly equally at both $\mathrm{C}_{(5)}$ and $\mathrm{C}_{(6)}$ positions to form 12-MBA trans-5,6-dihydrodiol with a $(5 S, 6 S) /(5 R, 6 R)$ enantiomer ratio of $57: 43$.
\end{abstract}

\section{INTRODUCTION}

Arene epoxides are the most abundant and one type of initial products formed in the metabolism of polycyclic aromatic hydrocarbons (PAHs) (Jerina \& Daly, 1974; Sims \& Grover, 1974). The formation of epoxides is catalysed by cytochrome $P-450$ isoenzymes in the drug-metabolizing enzyme complex. Other important components of the drug-metabolizing enzyme complex essential for drug oxidations are NADPH, NADPHcytochrome $P-450$ reductase and phosphatidylcholine (Lu \& West, 1980). Depending on its stability, an enzymically formed epoxide is hydrated to form a trans-dihydrodiol and/or is non-enzymically rearranged to form one or both of the two possible phenolic products. When epoxide hydrolase is inhibited by using an inhibitor such as TCPO, the enzymically formed epoxide is not hydrated to a trans-dihydrodiol and may remain as the epoxide if sufficiently stable. K-region epoxides of PAHs are generally more stable than non-K-region epoxides. By using the organic base triethylamine in the solvents for extraction and h.p.l.c. elution, we have successfully isolated K-region as well as non-K-region epoxides formed in the metabolisms of benzo $[a]$ pyrene (Yang \& Chiu, 1985), BA (Yang \& Chiu, 1985; Mushtaq et al., 1986) and, in the present study, 12-MBA. Since the enantiomers of K-region epoxides can be directly separated by c.s.p.-h.p.l.c. (Weems et al., 1985), the enantiomeric composition of a K-region 5,6-epoxide formed in the metabolism of a PAH by any PAH-metabolizing enzyme system can therefore be readily determined. Since the stereoheterotopic enzymesubstrate interaction determines the stereochemistry and optical purity of products formed, the enantiomeric composition of the metabolically formed $\mathrm{K}$-region 5,6-epoxide is therefore a direct measure of the stereoheterotopic interaction between the cytochrome $P-450$ isoenzyme and the $\mathrm{K}$-region double bond of a $\mathrm{PAH}$. In the present paper we describe the elucidation of the absolute configurations of enantiomeric 12-MBA 5,6-epoxide and 12-MBA trans-5,6-dihydrodiol. Enantiomeric compositions of both 12-MBA 5,6-epoxide and

\footnotetext{
Abbreviations used: PAH, polycyclic aromatic hydrocarbon; BA, benz[a]anthracene; 7,12-DMBA, 7,12-dimethylbenz[a]anthracene; 12-MBA, 12-methylbenz[a]anthracene; other monomethylbenz[a] anthracenes are similarly designated; 12-MBA trans-5,6-dihydrodiol, trans-5,6-dihydro-5,6dihydroxy-12-methylbenz[a]anthracene; 12-MBA 5,6-epoxide, 5,6-epoxy-5,6-dihydro-12-methylbenz[a]anthracene; PB, phenobarbital; MC, 3methylcholanthrene; TCPO, 3,3,3-trichloropropylene 1,2-oxide (3,3,3-trichloropropane 1,2-epoxide); $(R)$-DNBPG, $(R)$ - $N$-(3,5-dinitrobenzoyl)phenylglycine; $(S)$-DNBL, $(S)-N$-(3,5-dinitrobenzoyl)leucine; c.s.p., chiral stationary phase; n.O.e., nuclear Overhauser enhancement.

$\ddagger$ To whom correspondence and requests for reprints should be sent.
} 
12-MBA trans-5,6-dihydrodiol formed in the metabolism of 12-MBA by liver microsomal preparations (referred to below simply as 'microsomes') from untreated (control), PB-treated and MC-treated male Sprague-Dawley rats were determined by the c.s.p.-h.p.l.c. method. The results indicate that (i) cytochrome $P-450$ isoenzymes contained in all three rat liver microsomal preparations are stereoselective towards one of the two stereoheterotopic $\mathrm{K}$-region faces of 12-MBA, (ii) the methyl group in 12-MBA does not significantly alter the stereoselectivity of rat liver cytochrome $P-450$ isoenzymes in the epoxidation reactions at the K-region 5,6-double bond, and (iii) the regioselectivity of microsomal epoxide hydrolase is different depending on the absolute stereochemistry of the epoxide substrate.

\section{EXPERIMENTAL}

\section{Materials}

12-MBA was synthesized as described by Bradsher (1940). 12-MBA cis-5,6-dihydrodiol was synthesized by oxidation of 12-MBA with $\mathrm{OsO}_{4}$ (Harvey et al., 1975). $\mathrm{BF}_{3}$ etherate, methyl iodide, ethyl iodide and TCPO were purchased from Aldrich Chemical Co. (Milwaukee, WI, U.S.A.). NADP ${ }^{+}$, glucose 6-phosphate and glucose-6phosphate dehydrogenase (type XII) were obtained from Sigma Chemical Co. (St. Louis, MO, U.S.A.). Sodium methoxide, $\mathrm{NaH}, p-N N$-dimethylaminopyridine and triethylamine were purchased from Fisher Scientific Co. (Silver Spring, MD, U.S.A.). $\mathrm{PtO}_{2}, \mathrm{H}_{2} \mathrm{O}$ (Adams catalyst) was purchased from Alfa Products (Thiokol/Ventron Division, Danvers, MA, U.S.A.). Diethyl ether and h.p.l.c.-grade solvents were purchased from Mallinckrodt (Paris, KY, U.S.A.).

\section{H.p.l.c.}

H.p.l.c. was performed with a Waters Associates (Milford, MA, U.S.A.) liquid chromatograph consisting of a model $6000 \mathrm{~A}$ solvent-delivery system, a model M45 solvent-delivery system, a model 660 solvent programmer and a model 440 absorbance $(254 \mathrm{~nm}$ or $280 \mathrm{~nm})$ detector. Samples were injected via a Valco model N60 loop injector (Valco Instruments, Houston, TX, U.S.A.). Retention times and ratios of enantiomers, determined by areas under the chromatographic peaks, were recorded with a Hewlett-Packard model 3390A integrator.

Reversed-phase h.p.l.c. A DuPont (DuPont Co., Wilmington, DE, U.S.A.) Golden Series ODS (6.2 mm internal diam. $\times 8 \mathrm{~cm}$ ) column was used to purify and to analyse some derivatives of 12-MBA trans- and cis5,6-dihydrodiols. The column was eluted with a $15 \mathrm{~min}$ linear gradient from methanol/water $(3: 1, \mathrm{v} / \mathrm{v})$ to methanol at $1.5 \mathrm{ml} / \mathrm{min}$. The retention times are: trans-5,6-dihydro-5-hydroxy-6-methoxy-12-MBA and trans-5,6-dihydro-6-hydroxy-5-methoxy-12-MBA, 8.0 min; 5-hydroxy-12-MBA and 6-hydroxy-12-MBA, 10.6 min; trans-5-ethoxy-5,6-dihydro-6-methoxy-12-MBA and trans-6-ethoxy-5,6-dihydro-5-methoxy-12-MBA, $10.7 \mathrm{~min}$; 5-methoxy-12-MBA and 6-methoxy-12-MBA, $17.0 \mathrm{~min}$; 5-ethoxy-12-MBA, $17.6 \mathrm{~min}$. The retention times of two monomethyl ethers derived from 12 MBA cis-5,6-dihydrodiol under the same chromatographic conditions are 8.2 and $8.4 \mathrm{~min}$.
A Vydac $\mathrm{C}_{18}$ column ( $5 \mu \mathrm{m}$ particles; $4.6 \mathrm{~mm}$ internal diam. $\times 25 \mathrm{~cm}$; The Sep/a/ra/tion Group, Hesperia, CA, U.S.A.) was used to separate 5-methoxy-12-MBA and 6-methoxy-12-MBA. The elution solvent was methanol/water $(9: 1, \mathrm{v} / \mathrm{v})$ at $1.5 \mathrm{ml} / \mathrm{min}$. The retention times are: 6-methoxy-12-MBA, $9.3 \mathrm{~min}$; 5-methoxy-12MBA, $10.1 \mathrm{~min}$. These two methoxy derivatives of 12-MBA were not separable by using either a DuPont Zorbax ODS column $(4.6 \mathrm{~mm}$ internal diam. $\times 25 \mathrm{~cm})$ or a DuPont Golden Series Zorbax ODS column $(6.2 \mathrm{~mm}$ internal diam. $\times 8 \mathrm{~cm}$ ).

Normal-phase h.p.l.c. A DuPont Zorbax SIL column $(6.2 \mathrm{~mm}$ internal diam. $\times 25 \mathrm{~cm})$ was used to isolate the biosynthetic 12-MBA 5,6-epoxide. The chromatographic conditions are described below in the section on the preparation of biosynthetic 12-MBA 5,6-epoxide. A DuPont Golden Series SIL column $(6.2 \mathrm{~mm}$ internal diam. $\times 8 \mathrm{~cm}$ ) was also used to separate the methylation products of 12-MBA trans-5,6-dihydrodiol. The chromatographic conditions are described below in the section on the preparation of methylation products.

C.s.p.-h.p.l.c. This is basically a normal-phase operation. Analytical columns $(4.6 \mathrm{~mm}$ internal diam. $\times 25 \mathrm{~cm}$ ) packed with spherical particles of $5 \mu \mathrm{m}$ diameter of 3-aminopropylsilanized silica, to which either $(R)$-DNBPG or $(S)$-DNBL was either ionically or covalently bonded, were purchased from Regis Chemical Co. (Morton Grove, IL, U.S.A.). The enantiomers of 12-MBA 5,6-epoxide were separated with the ionically bonded $(S)$-DNBL column and the elution solvent was $0.5 \%(\mathrm{v} / \mathrm{v})$ of ethanol/acetonitrile $(2: 1, \mathrm{v} / \mathrm{v})$ in hexane at $2 \mathrm{ml} / \mathrm{min}$ (Weems et al., 1985). Enantiomers of 12-MBA trans-5,6-dihydrodiol were separated with an ionically bonded $(R)$-DNBPG column and the elution solvent was $10 \%(\mathrm{v} / \mathrm{v})$ of ethanol/acetonitrile $(2: 1, \mathrm{v} / \mathrm{v})$ in hexane at $2 \mathrm{ml} / \mathrm{min}$. The enantiomers of 12-MBA trans-5,6dihydrodiol were not separated on the covalently bonded $(R)$-DNBPG column or on the covalently and ionically bonded $(S)$-DNBL columns. 12-MBA 8,9-epoxide (retention time $10.7 \mathrm{~min}$ ) and 12-MBA 10,11-epoxide (retention time $9.2 \mathrm{~min}$ ) were separated by using the ionically bonded $(S)$-DNBL column with $0.5 \%(\mathrm{v} / \mathrm{v})$ of ethanol/acetonitrile $(2: 1, \mathrm{v} / \mathrm{v})$ in hexane at $2 \mathrm{ml} / \mathrm{min}$. Enantiomers of 12-MBA 8,9- and 10,11-epoxides were not separated by using any of the four c.s.p.-h.p.l.c. columns.

With an ionically bonded (S)-DNBL column and $1 \%$ $(\mathrm{v} / \mathrm{v})$ of ethanol/acetonitrile $(2: 1, \mathrm{v} / \mathrm{v})$ in hexane at $2 \mathrm{ml} / \mathrm{min}$, the enantiomers of both monomethyl ethers derived from 12-MBA trans-5,6-dihydrodiol (retention time $16.8 \mathrm{~min}$ ) were not separated. However, with the same column and elution solvent the enantiomers of one monomethyl ether (retention time $8.4 \mathrm{~min}$ on the ODS column; see above) derived from 12-MBA cis-5,6dihydrodiol are separated with retention times of 21.0 and $21.7 \mathrm{~min}$, with a resolution value of 0.4 . The enantiomers of another monomethyl ether (retention time $8.2 \mathrm{~min}$ on the ODS column) derived from 12-MBA cis-5,6-dihydrodiol have retention times of 25.8 and $30.6 \mathrm{~min}$, with a resolution value of 3.0 . Baseline separation is achieved with a resolution value of approximately 1.5 . The location of the methyl group in each of the two monomethyl ethers derived from 12-MBA cis-5,6-dihydrodiol was not established in this study. 


\section{Preparation of 5-methoxy-12-MBA and 6-methoxy-12-MBA}

12-MBA cis-5,6-dihydrodiol $(10 \mathrm{mg}$, dissolved in $2 \mathrm{ml}$ of acetone) was converted into a mixture of phenolic products by treatment with conc. $\mathrm{HCl}(0.2 \mathrm{ml})$ at $50^{\circ} \mathrm{C}$ for $1 \mathrm{~h}$. After the addition of water and neutralization with dil. $\mathrm{NaOH}$ solution, the phenolic products were extracted into ethyl acetate. The ethyl acetate phase was washed three times with water, dehydrated with anhydrous $\mathrm{MgSO}_{4}$, filtered and evaporated to dryness under reduced pressure. The phenolic products (dissolved in pyridine) were then converted into acetoxy compounds by the reaction with acetic anhydride at $70^{\circ} \mathrm{C}$ for $30 \mathrm{~min}$. A mixture of two acetoxy compounds was isolated, as a single chromatographic peak, by reversed-phase h.p.l.c., with methanol as the elution solvent. Purifed acetoxy compounds were then converted in methanolic $\mathrm{HCl}$ into a mixture of 5-methoxy-12-MBA and 6-methoxy-12MBA, which were separated on a Vydac $C_{18}$ column. The area ratios of chromatographic peaks, detected at $254 \mathrm{~nm}$, were approx. 1:9 in favour of 5-methoxy-12MBA. Repetitive chromatography yielded approx. $0.16 \mathrm{mg}$ of 6-methoxy-12-MBA and $1.3 \mathrm{mg}$ of 5-methoxy-12-MBA.

\section{Rat liver microsomes}

Male Sprague-Dawley rats (Charles Rivers Farm, Wilmington, MA, U.S.A.) weighing $100-200 \mathrm{~g}$ were treated intraperitoneally with $\mathrm{PB}(75 \mathrm{mg} / \mathrm{kg}$ body wt., injected in $0.5 \mathrm{ml}$ of water) once daily on each of three consecutive days, or with MC $(25 \mathrm{mg} / \mathrm{kg}$ body wt., injected in $0.5 \mathrm{ml}$ of corn oil) once daily for each of four consecutive days. The rats were killed the next day after the last injection of the drug, and liver microsomes were prepared as described previously (Alvares et al., 1970). Microsomal protein was determined by the method of Lowry et al. (1951), with bovine serum albumin as the protein standard.

\section{Preparation of biosynthetic 12-MBA trans-5,6-dihydrodiol}

12-MBA trans-5,6-dihydrodiol formed in the metabolism of 12-MBA by liver microsomes from untreated, PB-treated and MC-treated male Sprague-Dawley rats was isolated from a mixture of metabolites by reversedphase and normal-phase h.p.l.c. as previously described (Fu et al., 1982). A typical incubation in vitro was carried out as follows. 12-MBA ( $20 \mu \mathrm{mol}$ in $10 \mathrm{ml}$ of acetone) was incubated in the dark at $37^{\circ} \mathrm{C}$ for $1 \mathrm{~h}$ in a $250 \mathrm{ml}$ reaction mixture (pH 7.5) containing $12.5 \mathrm{mmol}$ of Tris $/ \mathrm{HCl}, 0.75 \mathrm{mmol}$ of $\mathrm{MgCl}_{2}, 25$ units of glucose6-phosphate dehydrogenase, $24 \mathrm{mg}$ of $\mathrm{NADP}^{+}, 160 \mathrm{mg}$ of glucose 6-phosphate and $250 \mathrm{mg}$ protein equivalent of liver microsomes from untreated, PB-treated or MCtreated rats. Residual substrate and metabolites were extracted with sequential additions of acetone $(250 \mathrm{ml})$ and ethyl acetate $(500 \mathrm{ml})$, and the organic phase was dried with anhydrous $\mathrm{MgSO}_{4}$, filtered and evaporated to dryness under reduced pressure.

For the purpose of determining the absolute configuration by the exciton-chirality method, a relative large amount (approx. $4.5 \mathrm{mg}$ ) of biosynthetic 12MBA trans-5,6-dihydrodiol highly enriched in the $5 S, 6 S$ enantiomer (see the Results section) was obtained, by multiple incubations in vitro $(8 \times 250 \mathrm{ml})$ of 12 -MBA with liver microsomes from MC-treated rats. The dihydrodiol was purified by a combination of normalphase h.p.l.c. and reversed-phase h.p.l.c. as described previously (Fu et al., 1982).

\section{Absolute configuration of enantiomeric 12-MBA trans-5,6-dihydrodiols}

$p-N N$-Dimethylaminobenzoyl chloride was prepared as described by Harada et al. (1975). The biosynthetic 12-MBA trans-5,6-dihydrodiol highly enriched in the $5 S, 6 S$ enantiomer was converted into a 5,6,8,9,10,11hexahydro-trans-5,6-diol by catalytic hydrogenation [tetrahydrofuran, $\mathrm{PtO}_{2} / \mathrm{H}_{2}, 400 \mathrm{kPa}\left(60 \mathrm{lbf} / \mathrm{in}^{2}\right), 16 \mathrm{~h}$ ] and each was purified by reversed-phase h.p.l.c. Bis- $p$ - $N N$-dimethylaminobenzoate derivatives of 12 MBA trans-5,6-dihydrodiol and its 5,6,8,9,10,11hexahydro-trans-5,6-diol hydrogenation product were prepared and subsequently purified by h.p.l.c. as described previously (Yang \& Fu, 1984a,b). Absolute configurations of the diols were determined by the exciton-chirality c.d. spectra of the resulting bis-esters (Harada \& Nakanishi, 1972). Diacetate derivatives were prepared by reaction of the diols with acetic anhydride in pyridine $\left(70^{\circ} \mathrm{C}, 30 \mathrm{~min}\right)$ and were purified by reversed-phase h.p.l.c.

\section{Preparation of biosynthetic 12-MBA 5,6-epoxide}

Enzymically formed K-region 5,6-epoxide of 12-MBA was isolated from a mixture of products formed by incubation of 12-MBA with liver microsomes prepared from untreated, PB-treated and MC-treated rats. The procedure is similar to that described previously (Mushtaq et al., 1986). A $150 \mathrm{ml}$ reaction mixture contained $150 \mathrm{mg}$ protein equivalent of rat liver microsomes, $7.5 \mathrm{mmol}$ of Tris/HCl (pH 7.5), $0.45 \mathrm{mmol}$ of $\mathrm{MgCl}_{2}, 15$ units of glucose-6-phosphate dehydrogenase, $15 \mathrm{mg}$ of NADP ${ }^{+}, 96 \mathrm{mg}$ of glucose 6-phosphate and $0.09 \mathrm{mmol}$ of the microsomal epoxide hydrolase inhibitor TCPO. The reaction mixture was pre-incubated at $37^{\circ} \mathrm{C}$ for $2 \mathrm{~min}$ in a water shaker bath. 12-MBA $(12 \mu \mathrm{mol}$ in $6 \mathrm{ml}$ of acetone) was then added and the mixture incubated for $30 \mathrm{~min}$. Residual 12-MBA and its metabolites were extracted by sequential additions of $150 \mathrm{ml}$ of acetone/triethylamine $(125: 1, \mathrm{v} / \mathrm{v})$ and $300 \mathrm{ml}$ of ethyl acetate/triethylamine (250:1, v/v). The resulting aqueous phase was extracted with an additional $300 \mathrm{ml}$ of ethyl acetate/triethylamine $(250: 1, \mathrm{v} / \mathrm{v})$. Organicsolvent extracts were combined and dehydrated with anhydrous $\mathrm{MgSO}_{4}$, filtered and evaporated to dryness under reduced pressure. The residue was redissolved in ethyl acetate/hexane/triethylamine (100:897:3, by vol.) for normal-phase-h.p.l.c. isolation of epoxides. 12-MBA 5,6-epoxides obtained from each $150 \mathrm{ml}$ incubation of 12-MBA with liver microsomes from untreated (control), PB-treated and MC-treated rats were determined to be 27,118 and $300 \mu \mathrm{g}$ respectively.

Biosynthetic 12-MBA 5,6-epoxide was isolated on a DuPont Zorbax SIL column $(6.2 \mathrm{~mm}$ internal diam. $\times 25 \mathrm{~cm}$ ) eluted with ethyl acetate/hexane/triethylamine (100:897:3, by vol.) for $16 \mathrm{~min}$ and followed by washing with ethyl acetate at $2 \mathrm{ml} / \mathrm{min}$. The eluate was monitored at $280 \mathrm{~nm}$. Isolated epoxides were dried under a stream of $\mathbf{N}_{2}$. 


\section{Enzymic hydration of biosynthetic 12-MBA 5,6-epoxide} enantiomers

Biosynthetic 12-MBA 5,6-epoxide formed in the incubations in vitro $(2 \times 150 \mathrm{ml})$ of 12 -MBA by liver microsomes from PB-treated rats was first isolated by normal-phase h.p.l.c. as described above and the enantiomeric 12-MBA 5,6-epoxides were then separated by c.s.p.-h.p.l.c. (Weems et al., 1985). Resolved enantiomers were each dissolved in acetone and converted into trans-dihydrodiols by incubation with rat liver microsomes from PB-treated rats in the absence of NADPH. The reaction mixture (5 $\mathrm{ml}$, in duplicates), which contained $50 \mathrm{nmol}$ of either 12-MBA $5 S, 6 R$-epoxide or 12-MBA $5 R, 6 S$-epoxide, $\quad 0.25 \mathrm{mmol}$ of Tris $/ \mathrm{HCl}$ (pH 7.5) and $5 \mathrm{mg}$ protein equivalent of rat liver microsomes, was incubated at $37^{\circ} \mathrm{C}$ for $30 \mathrm{~min}$ in a shaker water bath. After the reaction was stopped by the addition of $5 \mathrm{ml}$ of acetone, an internal standard (BA trans-5,6-dihydrodiol, $4.3 \mathrm{nmol}$ in $0.2 \mathrm{ml}$ of methanol) was added to each incubation mixture. This mixture was extracted with $10 \mathrm{ml}$ of ethyl acetate. The resulting organic phase was dehydrated with anhydrous $\mathrm{MgSO}_{4}$, filtered and evaporated to dryness under reduced pressure. Enantiomeric compositions of the dihydrodiol products were determined with an ionically bonded $(R)$-DNBPG column.

\section{Methoxylation of 12-MBA 5,6-epoxide}

12-MBA 5,6-epoxide (approx. $2 \mathrm{mg}$ ) was dissolved in methanol (approx. $3 \mathrm{ml}$ ) containing $2 \%(\mathrm{w} / \mathrm{v})$ of sodium methoxide and heated at $50^{\circ} \mathrm{C}$ for $48 \mathrm{~h}$. The products were partitioned with ethyl acetate $(25 \mathrm{ml})$ and water $(5 \mathrm{ml})$. The organic phase was washed three times with water, dried with anhydrous $\mathrm{MgSO}_{4}$ and evaporated to dryness under a stream of $\mathrm{N}_{2}$ at $50^{\circ} \mathrm{C}$. The residue was dissolved in ethyl acetate/hexane $(3: 17, \mathrm{v} / \mathrm{v})$ for normal-phase-h.p.l.c. separation of methoxylation products on a DuPont Zorbax SIL column (6.2 mm internal diam. $\times 25 \mathrm{~cm})$. The elution solvent was ethyl acetate/ methanol/hexane (10:1:189, by vol.) at $2 \mathrm{ml} / \mathrm{min}$. Two methoxylation products (with a ratio of area under the chromatographic peaks of $23: 77$, monitored at $280 \mathrm{~nm}$ ) were separated, with retention times of 19.8 and $20.3 \mathrm{~min}$. Two methoxylation products were also separated by using an ionically bonded ( $S$ )-DNBL column, eluted with $10 \%(\mathrm{v} / \mathrm{v})$ of ethanol/acetonitrile $(2: 1, \mathrm{v} / \mathrm{v}$ ) in hexane at $2 \mathrm{ml} / \mathrm{min}$ (see the Results section). The major methoxylation product, which is more retained on the SIL column, is less strongly retained by the ionically bonded (S)-DNBL column.

\section{Methylation of 12-MBA trans-5,6-dihydrodiol}

12-MBA trans-5,6-dihydrodiol (approx. $2 \mathrm{mg}$ ) formed in the metabolism of 12-MBA with liver microsomes from MC-treated rats was dissolved in $2 \mathrm{ml}$ of $\mathrm{NaH}$-treated tetrahydrofuran. Methyl iodide $(1.5 \mathrm{ml}$, diluted 1:1000 with $\mathrm{NaH}$-treated tetrahydrofuran) was added and the mixture was stirred for $30 \mathrm{~min}$ at room temperature. Methanol (approx. $2 \mathrm{ml}$ ) was added dropwise to quench the reaction. Solvent was evaporated and the residue was partitioned with ethyl acetate $(5 \mathrm{ml})$ and water $(2 \mathrm{ml})$. After being washed three times with water, the ethyl acetate phase was evaporated to dryness under a stream of $\mathrm{N}_{2}$. The residue, containing a mixture of two monomethyl ethers and a bis-methyl ether, as well as unchanged 12-MBA trans-5,6-dihydrodiol, was dissolved in tetrahydrofuran/methanol $(1: 1, \mathrm{v} / \mathrm{v})$ for normal-phase-h.p.l.c. separation on a DuPont Golden Series SIL column $(6.2 \mathrm{~mm}$ internal diam. $\times 8 \mathrm{~cm})$. The column was eluted with tetrahydrofuran/hexane $(1: 4$, $\mathrm{v} / \mathrm{v}$ ) at $2 \mathrm{ml} / \mathrm{min}$. The retention times are: bis-methyl ether $(29 \%), 1.5 \mathrm{~min}$; two monomethyl ethers $(55 \%)$, $2.4 \mathrm{~min}$; 12-MBA trans-5,6-dihydrodiol (16\%), $6.5 \mathrm{~min}$. Two monomethyl ethers were separated as described above. Two monomethyl ethers of 12-MBA cis-5,6dihydrodiol $\left(M^{+}\right.$at $m / z$ 290, with characteristic fragment ions at $m / z 275,273,259$ and 258) were similarly prepared.

\section{Location of the methyl group in monomethyl ethers}

In order to establish the position of the methoxy (or hydroxy) group in each of the two monomethyl ethers derived from 12-MBA 5,6-epoxide or 12-MBA trans5,6-dihydrodiol, the following methods were used in addition to n.m.r.-spectral analysis.

Method 1. Diethyl ether purchased from Mallinckrodt contains $96-98 \%$ of diethyl ether, $3.5 \%$ (max.) of ethanol, approx. $0.0001 \%$ of butylated hydroxytoluene added as a stabilizer and water. This ether was treated three times with shining $\mathrm{Na}$ metal to remove ethanol. If ethanol is not removed, the procedure described below will produce ethoxylated products. Each monomethyl ether was dissolved in $1 \mathrm{ml}$ of $\mathrm{Na}$-treated ether, and 20 drops (approx. $1 \mathrm{ml}$ ) of $\mathrm{BF}_{3}$ etherate were added. The mixture was purged with $\mathrm{N}_{2}$ and refluxed for $1.5 \mathrm{~h}$. Solvent was evaporated and the residue was dissolved in tetrahydrofuran/methanol $(1: 1, \mathrm{v} / \mathrm{v})$ for reversed-phaseh.p.l.c. by using a DuPont Golden Series ODS column $(6.2 \mathrm{~mm}$ internal diam. $\times 8 \mathrm{~cm})$, eluted with a $15 \mathrm{~min}$ linear gradient from methanol/water $(3: 1, \mathrm{v} / \mathrm{v})$ to methanol at $1.5 \mathrm{ml} / \mathrm{min}$.

Method 2. Each monomethyl ether was converted into an ethylated product by reaction with ethyl iodide in $\mathrm{NaH}$-treated tetrahydrofuran. The ethylated product was refluxed with $\mathrm{BF}_{3}$ etherate in ether as described in method 1. The products were also analysed by reversed-phase h.p.l.c. as described in method 1.

\section{Spectral analysis}

Mass-spectral analysis was performed on a Finnigan model 4000 gas chromatograph-mass spectrometer-data system with a solid probe by electron impact or by chemical ionization with methane as the ionization gas at $70 \mathrm{eV}$ and $250^{\circ} \mathrm{C}$ ionizer temperature. U.v.-visibleregion absorption spectra of samples were determined with a $1 \mathrm{~cm}$-path-length quartz cuvette with a Varian model Cary 118C spectrophotometer. High-resolution $(500 \mathrm{MHz})$ proton-n.m.r. spectra of samples, dissolved in $\left[{ }^{2} \mathrm{H}_{6}\right]$ acetone with a trace of ${ }^{2} \mathrm{H}_{2} \mathrm{O}$ to exchange hydroxy-group protons, were measured on a Bruker WM500 spectrometer. The chemical shifts are reported in parts per million (p.p.m.) downfield from tetramethylsilane by assigning the proton resonance of $\left[{ }^{3} \mathrm{H}_{5}\right]$ acetone at 2.06 p.p.m. Extensive homonuclear decoupling and n.O.e. experiments were performed in order to assign the chemical shifts of protons.

C.d. spectra of samples in a quartz cell of $1 \mathrm{~cm}$ path length at room temperature were measured with a Jasco model $500 \mathrm{~A}$ spectropolarimeter equipped with a model 


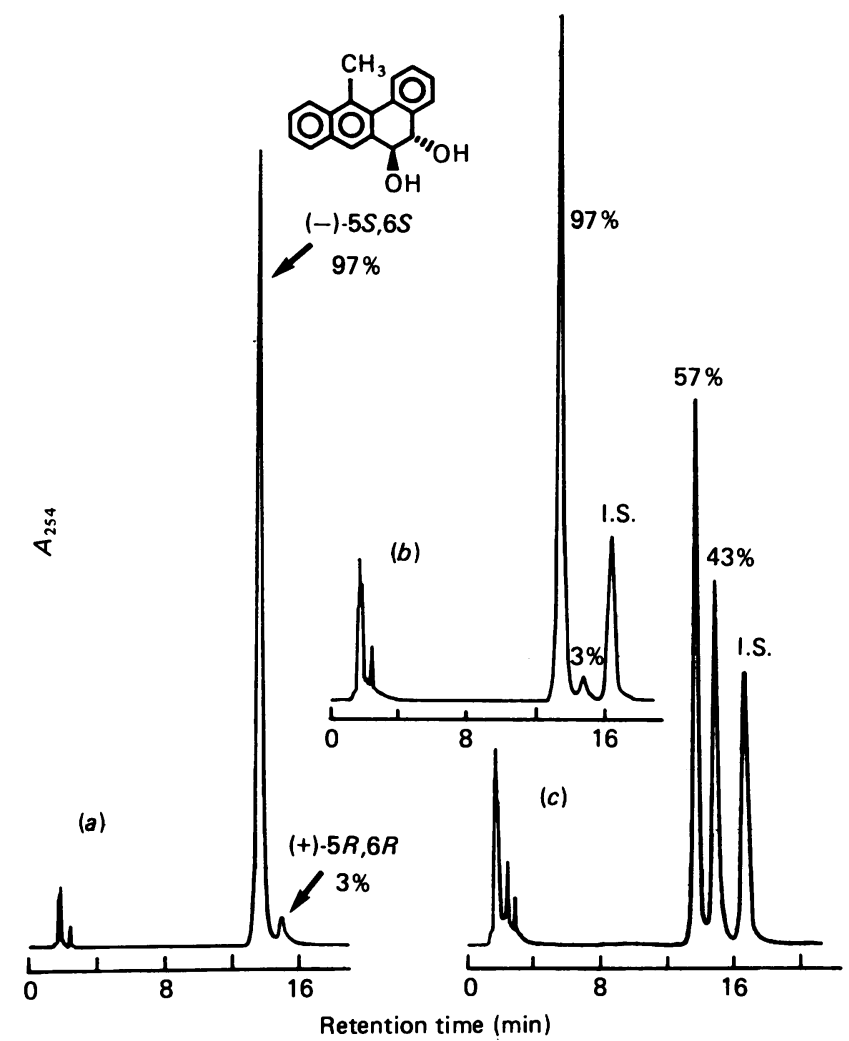

Fig. 1. C.s.p.-h.p.l.c. separation of 12-MBA trans-5,6dihydrodiol enantiomers formed $(a)$ in the metabolism of 12-MBA by liver microsomes from MC-treated rats, (b) in the hydration of optically pure 12-MBA $5 S, 6 R$-epoxide and $(c)$ in the hydration of optically pure 12-MBA $5 R, 6 S$-epoxide by liver microsomes from PB-treated rats in the absence of NADPH

See Fu et al. (1982) for the signs of optical rotation and the text of the present paper for the absolute configurations of enantiomers. I.S. indicates internal standard. Under the chromatographic conditions, 12-MBA 5,6-epoxide had a retention time of $5 \mathrm{~min}$. The column used was an ionically bonded $(R)$-DNBPG and the elution solvent was $10 \%$ $(\mathrm{v} / \mathrm{v})$ of ethanol/acetonitrile $(2: 1, \mathrm{v} / \mathrm{v})$ in hexane at $2 \mathrm{ml} / \mathrm{min}$.

DP-500 data processor. The concentration of the sample is indicated by $A_{\lambda 2} / \mathrm{ml}$ (absorbance units at wavelength $\lambda 2$ per $\mathrm{ml}$ of solvent). C.d. spectra are expressed by ellipticity $\left(\phi_{\lambda_{1}} / A_{\lambda 2}\right.$, in millidegrees) for solutions that have an absorbance of $A_{\lambda 2}$ unit (usually < 1.5) per $\mathrm{ml}$ of solvent at wavelength $\lambda 2$ (usually the wavelength of maximal absorption). Under conditions of measurements indicated above, the molecular ellipticity $([\theta])_{\lambda_{1}}$, in degrees $\left.\cdot \mathrm{cm}^{2} \cdot \mathrm{dmol}^{-1}\right)$ and ellipticity $\left(\phi_{\lambda_{1}} / \hat{A}_{\lambda 2}\right.$, in millidegrees) are related to the absorption coefficient $\left(\epsilon_{\lambda 2}\right.$, in $\left.\mathrm{M}^{-1} \cdot \mathrm{cm}^{-1}\right)$ as follows:

$$
[\theta]_{\lambda_{1}}=0.1 \epsilon_{\lambda_{2}}\left(\phi_{\lambda_{1}} / A_{\lambda 2}\right)
$$

\section{RESULTS}

\section{Absolute configuration and enantiomeric composition of metabolically formed 12-MBA trans-5,6-dihydrodiol}

A 12-MBA trans-5,6-dihydrodiol enriched in the $(-)-5 S, 6 S$ enantiomer was reported to be the product formed in the K-region (5,6-double bond) metabolism of 12-MBA by liver microsomes from MC-treated male Sprague-Dawley rats (Fu et al., 1982). In that study, the absolute configuration of the metabolically formed major 5,6-dihydrodiol enantiomer was deduced by comparing its c.d. spectrum with that of an enantiomeric BA $5 R, 6 R$-dihydrodiol (Fu et al., 1982). In this section, we describe the elucidation of absolute configuration by the exciton-chirality method (Harada \& Nakanishi, 1972).

The c.s.p.-h.p.l.c. method developed in our laboratory with the use of commercially available chiral columns in the direct (without prior derivative formation to give diastereomers) separation of enantiomeric mono-ol, diol and epoxide derivatives of many PAHs (Weems \& Yang, 1982; Yang \& Li, 1984; Yang \& Weems, 1984; Weems et al., 1985, 1986; Yang et al., 1984, 1986a,c) allowed us to determine the enantiomeric compositions of the metabolically formed 12-MBA trans-5,6-dihydrodiols (Fig. 1a). Resolved enantiomers have c.d. spectra that are mirror images of each other; the c.d. spectra of $5 S, 6 S$-dihydrodiol and 5S,6R-epoxide are shown (Fig. $2 a$ ). The $5 S, 6 S$ enantiomer was found to be the major 5,6-dihydrodiol enantiomer formed in the metabolism at the $\mathrm{K}$-region of 12-MBA by liver microsomes from untreated, PB-treated and MC-treated male SpragueDawley rats (Table 1).

In order to establish the absolute configuration unequivocally, a relatively large amount (approx. $4.5 \mathrm{mg}$ ) of a 12-MBA trans-5,6-dihydrodiol was obtained from a metabolite mixture by a large-scale $(8 \times 250 \mathrm{ml})$ incubation of 12-MBA with liver microsomes from MC-treated rats, and purified by a combination of normal-phase h.p.l.c. and reversed-phase h.p.l.c. as previously described (Fu et al., 1982). A portion of this 12-MBA trans-5,6-dihydrodiol (approx. $2 \mathrm{mg}$ ) was converted into a 5,6,8,9,10,11-hexahydro-trans-5,6-diol $\left(M^{+}\right.$at $m / z 280$; electron impact) by catalytic hydrogenation. C.d. spectra of both dihydrodiol and hexahydrodiol and their diacetates (Fig. $2 ; M^{+}$at $m / z 360$ and 364 respectively; electron impact) were consistent with the $5 S, 6 S$ stereochemistry; the sign of Cotton effects in the wavelength region approx. $225-245 \mathrm{~nm}$ in both diols was changed from negative to positive, reflecting the conformational changes (from preferentially quasidiequatorial to preferentially quasi-diaxial) upon acetylation (Yang \& Fu, 1984b). Furthermore, c.d. spectra of the bis- $p$ - $N N$-dimethylaminobenzoate derivatives of both dihydrodiol $\left[(M+1)^{+}\right.$at $m / z \quad 571$; chemical ionization] and hexahydrodiol $\left[(M+1)^{+}\right.$at $\mathrm{m} / z$ 575; chemical ionization] enantiomers indicated strong positive c.d. bands at $324 \mathrm{~nm}$ (Fig. 3). These positive c.d. chirality spectra provided definitive evidence that both the dihydrodiol and hexahydrodiol enantiomers under consideration have $5 S, 6 S$ absolute stereochemistry (Harada \& Nakanishi, 1972). Similar approaches were taken to elucidate the absolute configurations of enantiomeric K-region trans-5,6-dihydrodiols of BA (Thakker et al., 1979; Yang \& Fu, 1984b), 7,12-DMBA (Yang \& Fu, 1984b) and chrysene (Weems et al. 1986). The results in Fig. 3 support our earlier findings that saturation of the non-bay-region terminal benzo ring of the K-region trans- and cis-dihydrodiol enantiomers of BA and other methyl- or halogen-substituted BA derivatives is not necessary before the determination of absolute configuration by the exciton-chirality c.d. 

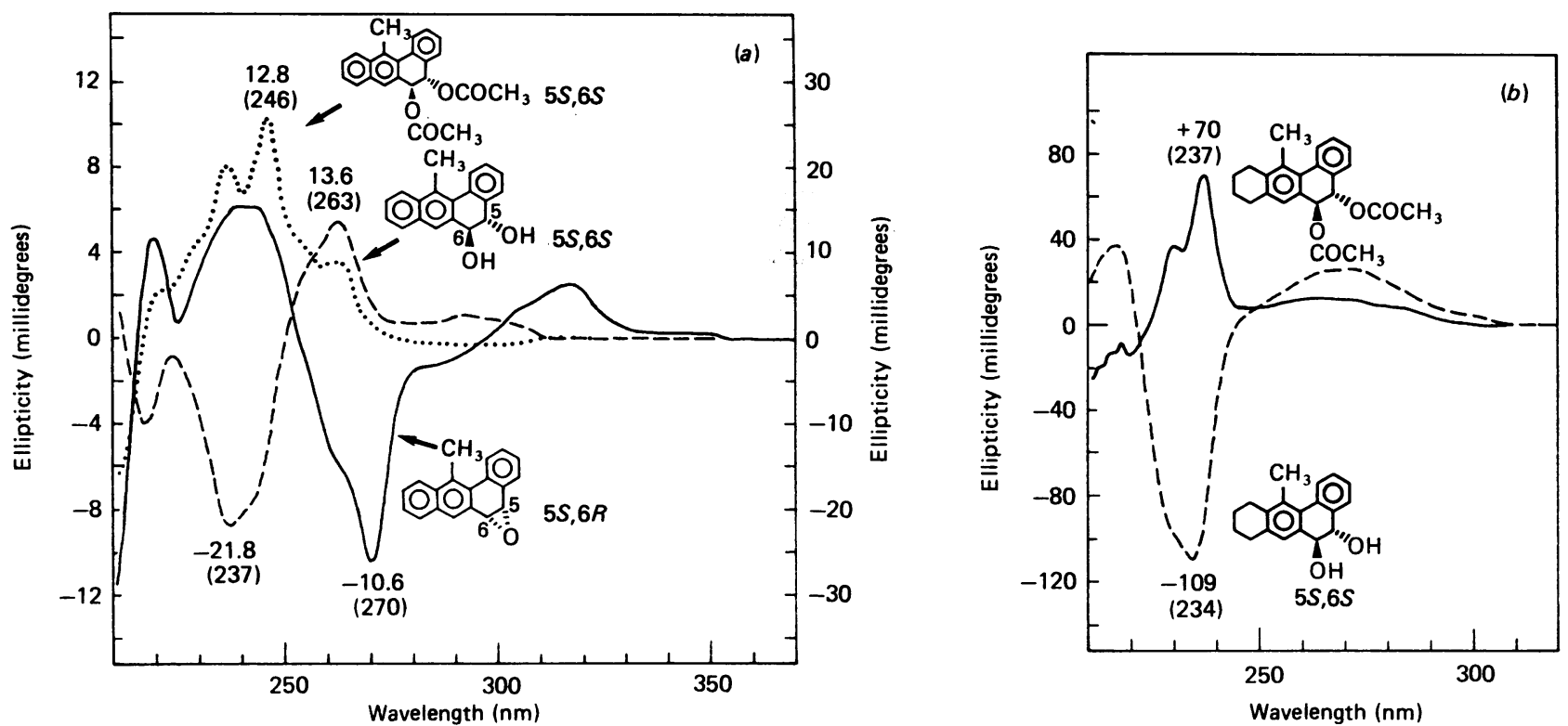

Fig. 2. (a) C.d. spectra of 12-MBA trans-5S,6S-dihydrodiol (----, right-hand axis; enantiomeric excess $98 \% ;$ concn. $1.0 A_{265}$ unit/ml, in methanol) and its diacetate $\left(\cdots \cdots\right.$, left-hand axis; concn. $1.0 A_{265}$ unit/ml, in methanol) and 12-MBA 5S,6R-epoxide $(-$ left-hand axis; enantiomeric excess $98 \%$; concn. $1.0 A_{271}$ unit/ml, in hexane), and (b) c.d. spectra of 12-MBA 5,6,8,9,10,11hexahydro-5S,6S-diol (----; enantiomeric excess $94 \%$; concn. $1.0 A_{222}$ unit/ml, in methanol) and its diacetate (-; concn. $1.0 A_{273}$ unit/ml, in methanol)

Table 1. Stereoselective formation and hydration of 5,6-epoxide in the metabolism of BA and 12-MBA by rat liver microsomes

Metabolically formed 5,6-epoxide and 5,6-dihydrodiol were obtained by incubation of 12-MBA with rat liver microsomes and an NADPH-generating system in the presence and in the absence of TCPO respectively. Enantiomeric compositions of both epoxide and dihydrodiol were determined by c.s.p.-h.p.l.c.

\begin{tabular}{|c|c|c|c|c|c|}
\hline \multirow{3}{*}{$\begin{array}{l}\text { Rats from } \\
\text { which microsomes } \\
\text { were obtained }\end{array}$} & \multirow[b]{3}{*}{ Substrate } & \multicolumn{4}{|c|}{ Enantiomeric composition $(\%)$} \\
\hline & & \multicolumn{2}{|c|}{ 5,6-Epoxide } & \multicolumn{2}{|c|}{ trans-5,6-Dihydrodiol } \\
\hline & & $5 S, 6 R$ & $5 R, 6 S$ & $5 S, 6 S$ & $5 R, 6 R$ \\
\hline Control (untreated) & 12-MBA & 73 & 27 & 93 & 7 \\
\hline Control (untreated) & BA & $75(53)^{*}$ & $25(47)^{*}$ & 23 & 77 \\
\hline PB-treated & 12-MBA & 78 & 22 & 88 & 12 \\
\hline PB-treated & BA & $79(55)^{*}$ & $* 21(45)^{*}$ & 18 & 82 \\
\hline MC-treated & 12-MBA & 99 & 1 & 97 & 3 \\
\hline MC-treated & BA & $96(97)^{*}$ & * $4(3)^{*}$ & 16 & 84 \\
\hline PB-treated & 12-MBA 5S,6R-epoxide & - & - & 97 & 3 \\
\hline PB-treated & BA $5 S, 6 R$-epoxide & - & - & 10 & 90 \\
\hline PB-treated & 12-MBA $5 R, 6 S$-epoxide & - & - & 57 & 43 \\
\hline PB-treated & BA $5 R, 6 S$-epoxide & - & - & 65 & 35 \\
\hline
\end{tabular}

* Data on K-region metabolism of BA are taken from Yang \& Chiu (1985) and Mushtaq et al. (1986), who used rat liver microsomes prepared at different times.

method (Fu \& Yang, 1983; Yang \& Fu, 1984a,b; Chiu et al., 1984; Yang et al., 1986a,b,c).

\section{Isolation of biosynthetic 12-MBA epoxides}

A mixture of metabolites containing 12-MBA 5,6-, 8,9and 10,11-epoxides was obtained by incubation of 12-MBA with liver microsomes from MC-treated rats in the presence of an epoxide hydrolase inhibitor, TCPO. The epoxides were isolated by normal-phase h.p.l.c. (Fig. 4) on a silica-gel column with an elution solvent containing ethyl acetate, hexane and triethylamine as previously described (Mushtaq et al., 1986). 12-MBA 5,6-epoxide (peak 2 of Fig. 4) was the major epoxide isolated under the experimental conditions used. A mixture of 8,9- and 10,11-epoxides (peak 3 of Fig. 4) was also isolated. The ratio of areas under the chromatographic peaks 2 and 3, monitored at $280 \mathrm{~nm}$, was found to be 15:2. 12-MBA 8,9- and 10,11-epoxides in peak 3 were separated on an ionically bonded $(S)$-DNBL column [retention times 10.7 and $9.2 \mathrm{~min}$ respectively; elution solvent, $0.5 \%(\mathrm{v} / \mathrm{v})$ of ethanol/acetonitrile $(2: 1$, $\mathrm{v} / \mathrm{v}$ ) in hexane; flow rate, $2 \mathrm{ml} / \mathrm{min}]$. The ratio of the 


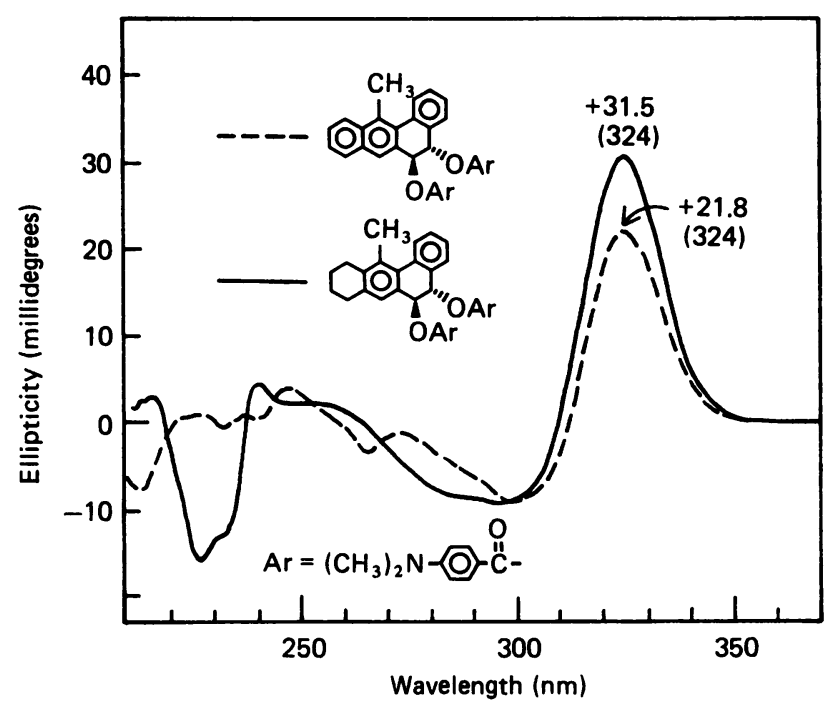

Fig. 3. C.d. spectra of the bis-p-NN-dimethylaminobenzoate derivatives of 12-MBA trans-5,6-dihydrodiol formed in the metabolism of 12-MBA by liver microsomes from MC-treated rats (----; enantiomeric excess 98\%; concn. $1.0 A_{312}$ unit $/ \mathrm{ml}$, in methanol) and of its 5,6,8,9,10,11-hexahydro-5,6-diol (-; concn. $1.0 A_{315}$ unit/ml, in methanol)

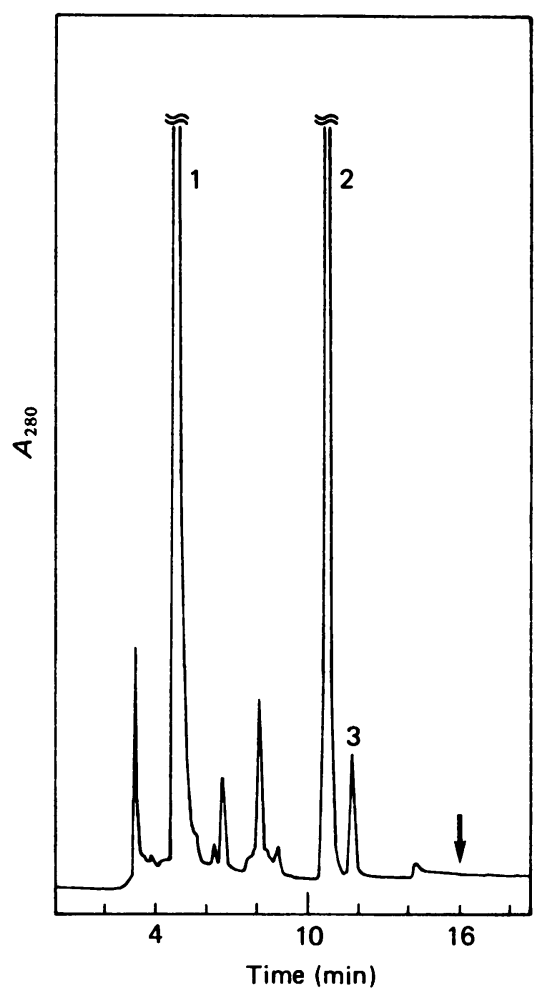

Fig. 4. Normal-phase h.p.l.c. separation of 12-MBA and its Kand non-K-region epoxide metabolites

The sample was obtained by incubation of 12-MBA with liver microsomes from MC-treated rats in the presence of TCPO (see the Experimental section). The identities of the chromatographic peaks are: 1, 12-MBA; 2, 12-MBA 5,6-epoxide; 3, a mixture of 12-MBA 8,9-and 10,11epoxides. At the time indicated by the arrow, ethyl acetate was used to elute the phenolic metabolites. (a)

(b)

(c)

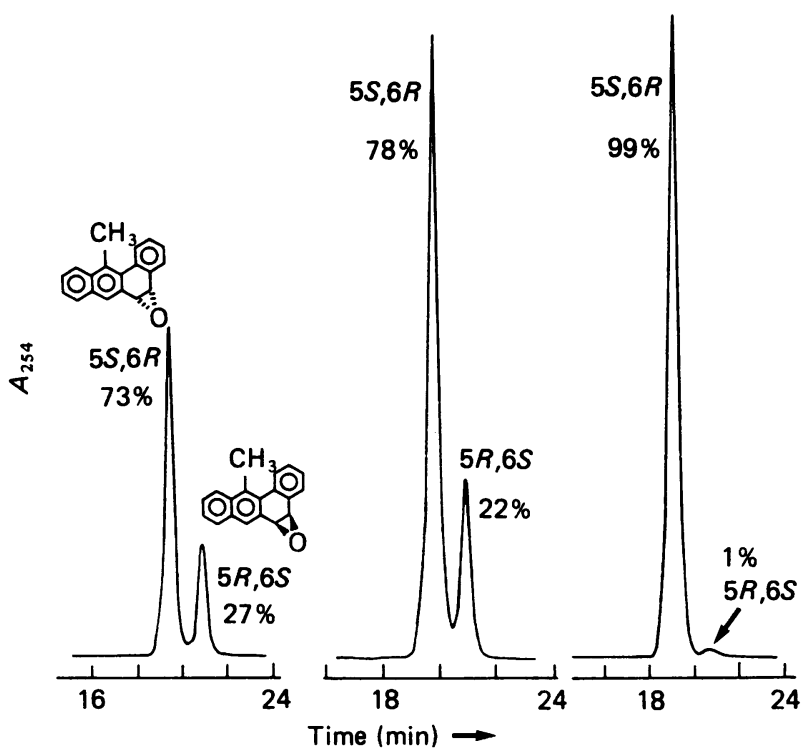

Fig. 5. C.s.p.-h.p.l.c. determination of enantiomeric compositions of 12-MBA 5,6-epoxides formed in the metabolism of 12-MBA by liver microsomes from untreated $(a)$, PB-treated (b) and MC-treated (c) rats

The metabolically formed 5,6-epoxide was isolated as described in Fig. 4. An ionically bonded (S)-DNBL column was used. The elution solvent was $0.5 \%(\mathrm{v} / \mathrm{v})$ of ethanol/acetonitrile $(2: 1, \mathrm{v} / \mathrm{v})$ in hexane at $2 \mathrm{ml} / \mathrm{min}$.

areas under the chromatographic peaks of 8,9-epoxide and 10,11-epoxide, detected at $280 \mathrm{~nm}$, was found to be $1: 6$. The enantiomers of 8,9-epoxide and of 10,11 -epoxide were not separated by the ionically bonded $(S)$-DNBL column.

The identities of the metabolically formed 5,6-, 8,9and 10,11-epoxides were established by u.v.-visibleregion absorption and mass-spectral analyses similar to those described previously (Mushtaq et al., 1986). Furthermore, when each metabolically formed epoxide was incubated with liver microsomes from PB-treated rats in the absence of NADPH, a corresponding trans-dihydrodiol was obtained. Similarly to those found in BA metabolism, c.d.-spectral analyses (not shown) of the metabolically formed 12-MBA 8,9- and 10,11epoxides were similar to those of BA $8 R, 9 S$ - and $10 S, 11 R$-epoxide enantiomers respectively (Mushtaq et al., 1986). The experimental procedures described in this and a previous paper (Mushtaq et al., 1986) did not cause racemization of the metabolically formed 12-MBA 8,9- and 10,11-epoxides. Enantiomeric 1,2and 3,4-epoxides of phenanthrene, chrysene and benzo[c]phenanthrene are known to undergo spontaneous racemization (Boyd \& Stubbs, 1983).

\section{Enantiomeric compositions of metabolically formed 12-MBA 5,6-epoxides}

The enantiomers of 12-MBA 5,6-epoxide can be resolved by any one of four different c.s.p.-h.p.l.c. columns (Weems et al., 1985). 12-MBA 5,6-epoxides, formed in the metabolism of 12-MBA by liver microsomes from untreated, PB-treated and MC-treated rats, 
were isolated by normal-phase h.p.l.c. (Fig. 4), and their enantiomeric compositions were determined by c.s.p.h.p.l.c. (Fig. 5 and Table 1). The metabolically formed 12 -MBA 5,6 -epoxides contained at least $73 \%$ of the $5 S, 6 R$ enantiomer (see below for the elucidation of absolute configuration), whose c.d. spectrum is shown in Fig. 2(a).

\section{Enzymic hydration mechanisms of optically pure 12-MBA 5,6-epoxide enantiomers}

Incubations in vitro $(2 \times 150 \mathrm{ml})$ of 12 -MBA with liver microsomes from PB-treated rats was carried out. 12-MBA 5,6-epoxide was purified by normal-phase h.p.l.c. (Fig. 4). Its enantiomers were separated by c.s.p.-h.p.l.c. (Fig. 5). These procedures yielded approx. $470 \mu \mathrm{g}$ of $5 S, 6 R$-epoxide and approx. $130 \mu \mathrm{g}$ of $5 R, 6 S-$ epoxide. Each of the 12-MBA 5,6-epoxide enantiomers was incubated with liver microsomes from PB-treated rats in the absence of NADPH. Under the experimental conditions, each of the epoxide enantiomers was completely converted into a dihydrodiol. For the purpose of monitoring the yield of the dihydrodiol product, an internal standard (BA trans-5,6-dihydrodiol) was added after the reaction has been stopped by the addition of acetone. The enantiomeric compositions of the resulting 12-MBA trans-5,6-dihydrodiols were each determined by c.s.p.-h.p.l.c. (Fig. 1). The optically pure 12-MBA $5 S, 6 R$-epoxide was enzymically converted into a trans-5,6-dihydrodiol with a $(5 S, 6 S) /(5 R, 6 R)$ enantiomer ratio of $97: 3$ (Fig. $1 b$ ). In comparison, the optically pure 12-MBA $5 R, 6 S$-epoxide was enzymically converted into a trans-5,6-dihydrodiol with a $(5 S, 6 S) /(5 R, 6 R)$ enantiomer ratio of 57:43 (Fig. 1c). Because of the limited amount of 12-MBA 5,6-epoxide obtainable by the biosynthetic method, the kinetics of enzymic hydration of the enantiomeric 5,6-epoxides could not be studied at the present time. Since an internal standard was used, the percentage of epoxide recovered as dihydrodiol can be determined: approx. $90 \%$ for $5 S, 6 R$-epoxide and approx. $77 \%$ for $5 R, 6 S$-epoxide. Possible non-enzymic rearrangement products of 12-MBA 5,6-epoxide, 5- and 6-hydroxy-12-MBA, were not detected.

\section{Absolute configuration of 12-MBA 5,6-epoxide enantiomers}

An important part of this investigation is to determine the absolute configuration of 12-MBA 5,6-epoxide enantiomers. Without the knowledge of the relationship between c.d. spectra and absolute configurations of $\mathrm{K}$-region epoxide enantiomers, it is not possible to determine the exact extent of stereoheterotopic enzyme (cytochrome $P-450$ isoenzyme)-substrate (12-MBA) interaction resulting in the stereoselective formation of $\mathrm{K}$-region epoxide.

A large-scale $(6 \times 150 \mathrm{ml})$ incubation in vitro of 12-MBA with liver microsomes from MC-treated rats was carried out to prepare approx. $1.8 \mathrm{mg}$ of 12-MBA 5,6-epoxide. The epoxide, highly enriched in the $5 S, 6 R$ enantiomer (Fig. 5), was purified by normal-phase h.p.l.c. (Fig. 4). The purified 12-MBA 5,6-epoxide was dissolved in a methanol solution containing sodium methoxide and heated at $70^{\circ} \mathrm{C}$ for $48 \mathrm{~h}$. A mixture of two methoxylated products was purified by normal-phase h.p.l.c. (chromatogram not shown). The enantiomers of the two methoxylated products were then separated by c.s.p.-h.p.l.c. on an ionically bonded ( $S$ )-DNBL column (Fig. 6a, upper chromatogram). Repetitive chromatography yielded chromatographically pure compounds E1, E2 and E3 [E3 contained a small amount (approx. $1 \%$ ) of its enantiomer D3]. Mass-spectral analyses of the compounds contained in peaks E1, E2 and E3 indicated that they all have molecular ions at $\mathrm{m} / z 290$ with characteristic fragment ions at $\mathrm{m} / z 275\left(\right.$ loss of $\left.\mathrm{CH}_{3}\right)$ and 258 (loss of $\mathrm{CH}_{3} \mathrm{OH}$ ). C.d.-spectral analyses indicated that the compounds in peaks E1 and E2 are a pair of enantiomers [the c.d. spectrum of peak E2 is shown in Fig. 6(c)]. The area under peak E1 is approx. $1 \%$ of that of peak E2 (Fig. 6a). The c.d. spectrum of the peak E2 compound exhibited Cotton effects that were opposite in signs, but were not exact mirror images, as those of the E3 compound (Figs. $6 c$ and $6 d$ ).

A 12-MBA trans-5,6-dihydrodiol highly enriched in the $5 S, 6 S$ enantiomer (Fig. 1a), formed in the metabolism of 12-MBA by liver microsomes from MC-treated rats and isolated by normal-phase h.p.l.c. and reversed-phase h.p.l.c. (Fu et al., 1982), was dissolved in $\mathrm{NaH}$-treated tetrahydrofuran and converted into a pair of methylated products by reaction with methyl iodide. The enantiomers of two methylated products were separated by c.s.p.-h.p.l.c. on an ionically bonded (S)-DNBL column (Fig. $6 a$, lower chromatogram). Again, repetitive chromatography yielded chromatographically pure compounds D1, D2 and D3. The compounds in peaks D1 and D2 are a pair of enantiomers that have retention times and c.d. spectra identical with those of the compounds in peaks E1 and E2 respectively (Figs. $6 b$ and $6 c$ ). The c.d. spectrum of the peak D3 compound is an exact mirror image of that of the peak E3 compound (Fig. 6d).

The methoxylation products and their enantiomers derived from 12-MBA 5,6-epoxide have retention times on reversed-phase h.p.l.c., normal-phase h.p.l.c. and c.s.p.-h.p.l.c. identical with those of the methylation products derived from 12-MBA trans-5,6-dihydrodiol and its enantiomers. These results indicate that the methoxy and the hydroxy groups of both of the methoxylation products, derived by the reaction of sodium methoxide with 12-MBA 5,6-epoxide, have trans relationship. N.m.r.-spectral data (see below) confirm this conclusion.

The results presented above indicated that a trans5,6-dihydro-6(or 5)-S-hydroxy-5(or 6)-S-methoxy-12MBA $(77 \%)$ and a trans-5,6-dihydro-5(or 6)- $R$ hydroxy-6(or 5)- $R$-methoxy-12-MBA $(23 \%)$ were predominantly formed by the reaction of sodium methoxide with the 12-MBA, 5,6-epoxide that was derived metabolically from 12-MBA by liver microsomes from MCtreated rats (Fig. 6a). Direct methylation of 12-MBA trans-5,6-dihydrodiol yielded the same two products in a ratio of 43:57 (Fig. 6a). The mechanisms of methoxylation/methylation reactions described above are shown in Fig. 6(b); the structures of the compounds in peak E2 and peak E3 have been found by chemical and n.m.r.-spectral analyses (see below) to be trans-5,6dihydro-5-hydroxy-6-methoxy-12-MBA and trans-5,6dihydro-6-hydroxy-5-methoxy-12-MBA respectively. On the basis of these results, the predominant enantiomer of the 5,6-epoxide formed in the metabolism of 12-MBA by liver microsomes from MC-treated rats was deduced to have a $5 S, 6 R$ absolute stereochemistry (Fig. $6 b$ ). 


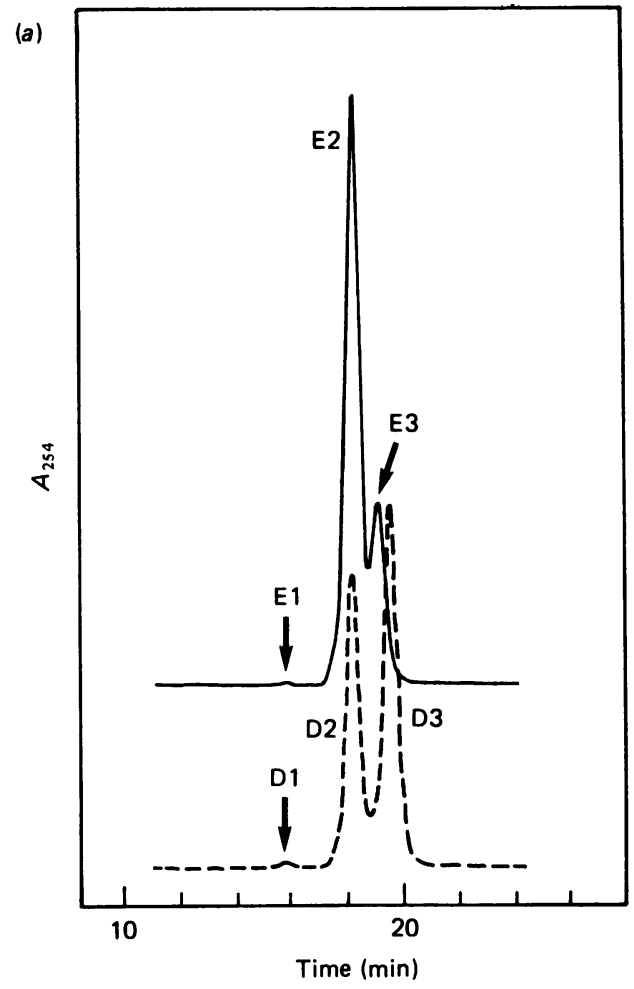

(b)<smiles>Cc1c2cccc1-c1ccccc1C(=O)O2</smiles>

$5 S, 6 R$

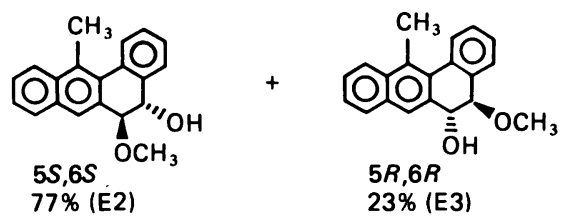

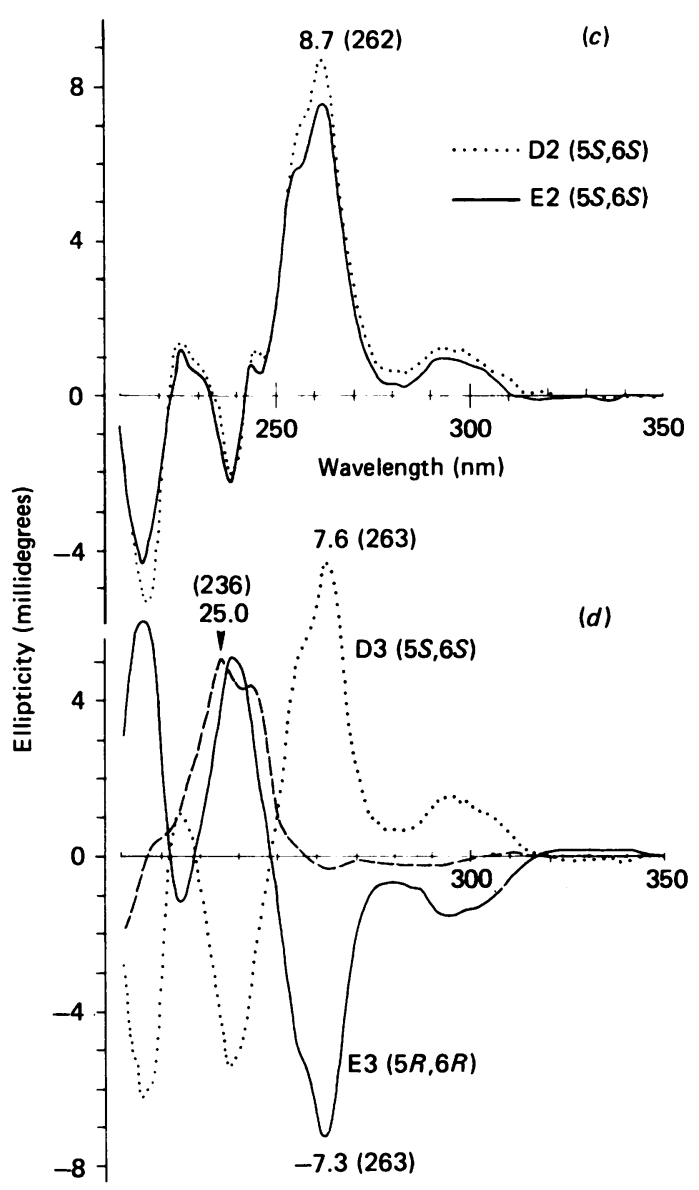

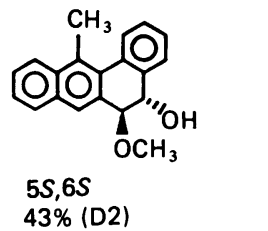<smiles>CO[C@H]1c2ccccc2-c2ccccc2[C@H]1O</smiles>

Fig. 6. H.p.l.c. separation, structures and c.d. spectra of monomethyl ethers derived from enantiomeric 12-MBA 5,6-epoxides

(a) H.p.l.c. separation of monomethyl ethers on an ionically bonded $(S)$-DNBL column $(4.6 \mathrm{~mm}$ internal diam. $\times 25 \mathrm{~cm})$ with as elution solvent $1 \%(\mathrm{v} / \mathrm{v})$ of ethanol/acetonitrile $(2: 1, \mathrm{v} / \mathrm{v})$ in hexane at $2 \mathrm{ml} / \mathrm{min}$. Samples of 12-MBA 5,6-epoxide with a $(5 S, 6 R) /(5 R, 6 S)$ ratio of $99: 1$ ( -$)$ and 12-MBA trans-5,6-dihydrodiol with a $(5 S, 6 S) /(5 R, 6 R)$ ratio of $97: 3(---)$ were used in the methoxylation and methylation reactions respectively. Peaks E1/E2, D1/D2 and E3/D3 are each an enantiomeric pair. (b) Stereochemistry of the methoxylation products derived from 12-MBA $5 S, 6 R$-epoxide and the methylation products derived from 12-MBA trans-5S,6S-dihydrodiol. The product ratios were determined by areas under the chromatographic peaks as described in $(a)$. Structures of monomethyl ethers derived from $5 R, 6 S$-epoxide and $5 R, 6 R$-dihydrodiol are not shown. Peaks E2, E3, D2 and D3 indicate the chromatographic peaks separated as shown in $(a)$. (c) C.d. spectra of methoxylation product E2 (-; concn. $1.0 A_{265}$ unit $/ \mathrm{ml}$, in methanol) and methylation product D2 $\left(\cdots ;\right.$; concn. $1.0 A_{265}$ unit $/ \mathrm{ml}$, in methanol). Both products were optically pure and were isolated by repetitive chromatography as described in $(a)$. (d) C.d. spectra of methoxylation product E3 (- concn. $1.0 A_{265}$ unit/ml, in methanol) and methylation product D3 $\left(\cdots \cdots ;\right.$ concn. $1.0 A_{265}$ unit $/ \mathrm{ml}$, in methanol) isolated as described in $(a)$. The c.d. spectrum (the scale of ellipticity is reduced by 5 -fold) of the bis-methyl ether was derived from 12-MBA $5 S, 6 S$-dihydrodiol (----, concn. $1.0 A_{268}$ unit/ml, in methanol).

\section{Structures of two monomethyl ethers determined by chemical methods}

The methoxylation products (peaks E2 and E3 of Fig. 6a) formed were each refluxed in $\mathrm{BF}_{3}$ etherate (see the
Experimental section). Products formed were separated by reversed-phase h.p.l.c. The major product derived from peak E2 of Fig. 6(a) was found to be 5-hydroxy12-MBA, resulting from the loss of a $\mathrm{CH}_{3} \mathrm{OH}$ molecule. By similar procedure, the major product formed from 


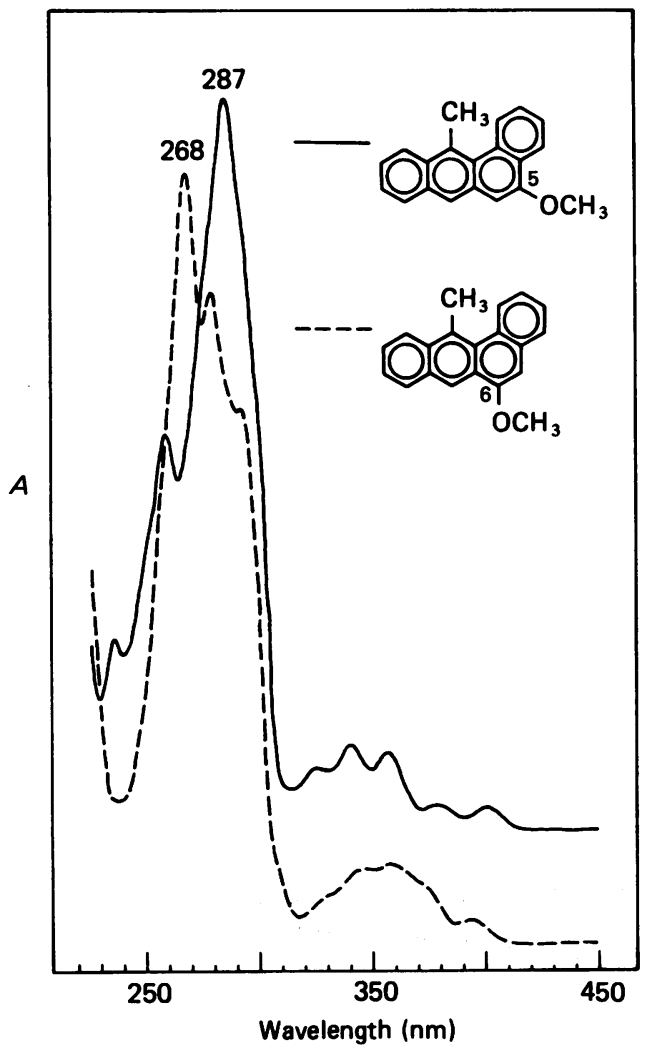

Fig. 7. U.v.-visible-region absorption spectra of 5-methoxy12-MBA $(\longrightarrow)$ and 6-methoxy-12-MBA (--) in methanol

The absorption characteristics were not changed when the compounds were dissolved in methanolic $\mathrm{NaOH}$.

peak E3 of Fig. 6(a) was found to be 5-methoxy-12-MBA $\left(M^{+}\right.$at $m / z 272$, resulting from the loss of a $\mathrm{H}_{2} \mathrm{O}$ molecule) with a u.v. absorption spectrum identical with that of the chemically synthesized 5-methoxy-12-MBA (Fig. 7). Identical results were obtained when peaks D2 and D3 of Fig. 6(a) were used.

A second method employed was to convert the compound in peak E2 (E3) into an ethylation product by reaction with ethyl iodide in $\mathrm{NaH}$-treated tetrahydrofuran. The ethylation product of the peak E2 compound, a 5-ethoxy-6-methoxy-5,6-dihydro-12-MBA $\left(M^{+}\right.$at $m / z$ 318; electron impact), was then refluxed in $\mathrm{BF}_{3}$ etherate. The resulting product was analysed by reversed-phase h.p.l.c. and a 5-ethoxy-12-MBA $\left(M^{+}\right.$at $m / z$ 286; electron impact) was found to be the major product. The u.v. absorption spectrum of 5-ethoxy12-MBA (not shown) exhibited similar absorption characteristics to that of 5-methoxy-12-MBA. However, the ethylation product of the peak E3 compound, a 6-ethoxy-5,6-dihydro-5-methoxy-12-MBA $\left(M^{+}\right.$at $m / z$ 318 ), did not yield any identifiable products. Nevertheless, the result obtained above indicated that the methoxy groups of the compounds in peaks E2 and E3 are at the $C_{(6)}$ and $C_{(5)}$ positions respectively. Since the absolute configurations of the compounds in peaks E2 and E3 have been determined [see the c.d. spectra in Figs. $6(c)$ and $6(d)]$, the locations of methoxy groups and hydroxy groups of the compounds in peaks E2 and E3 provided evidence that the major 12-MBA 5,6-epoxide

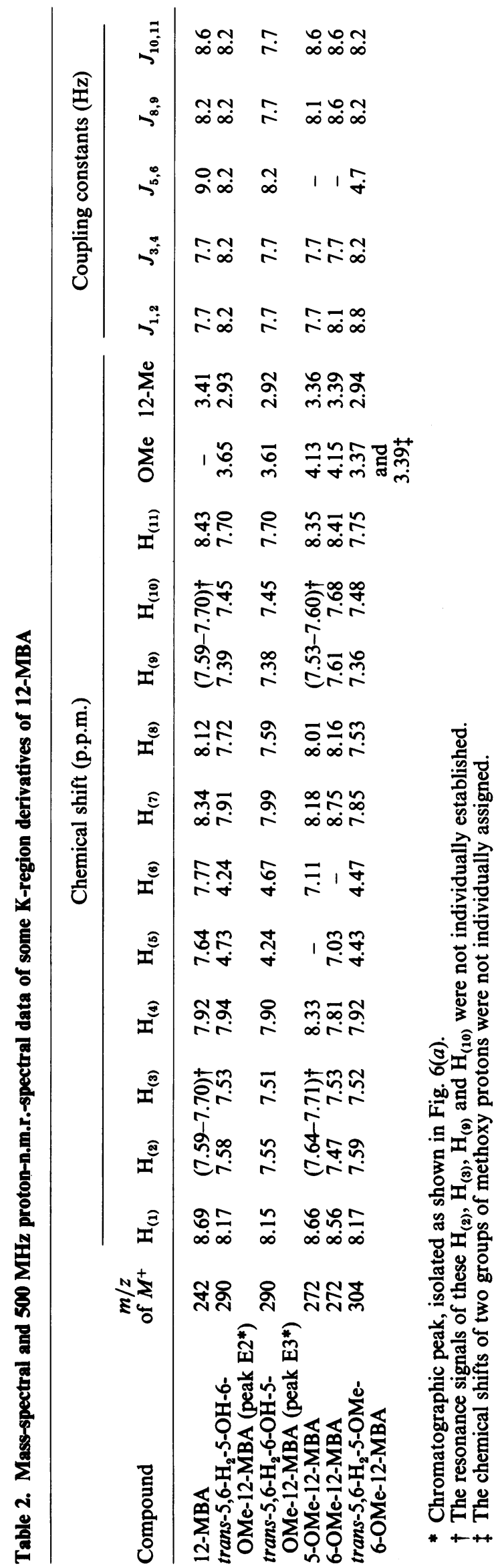



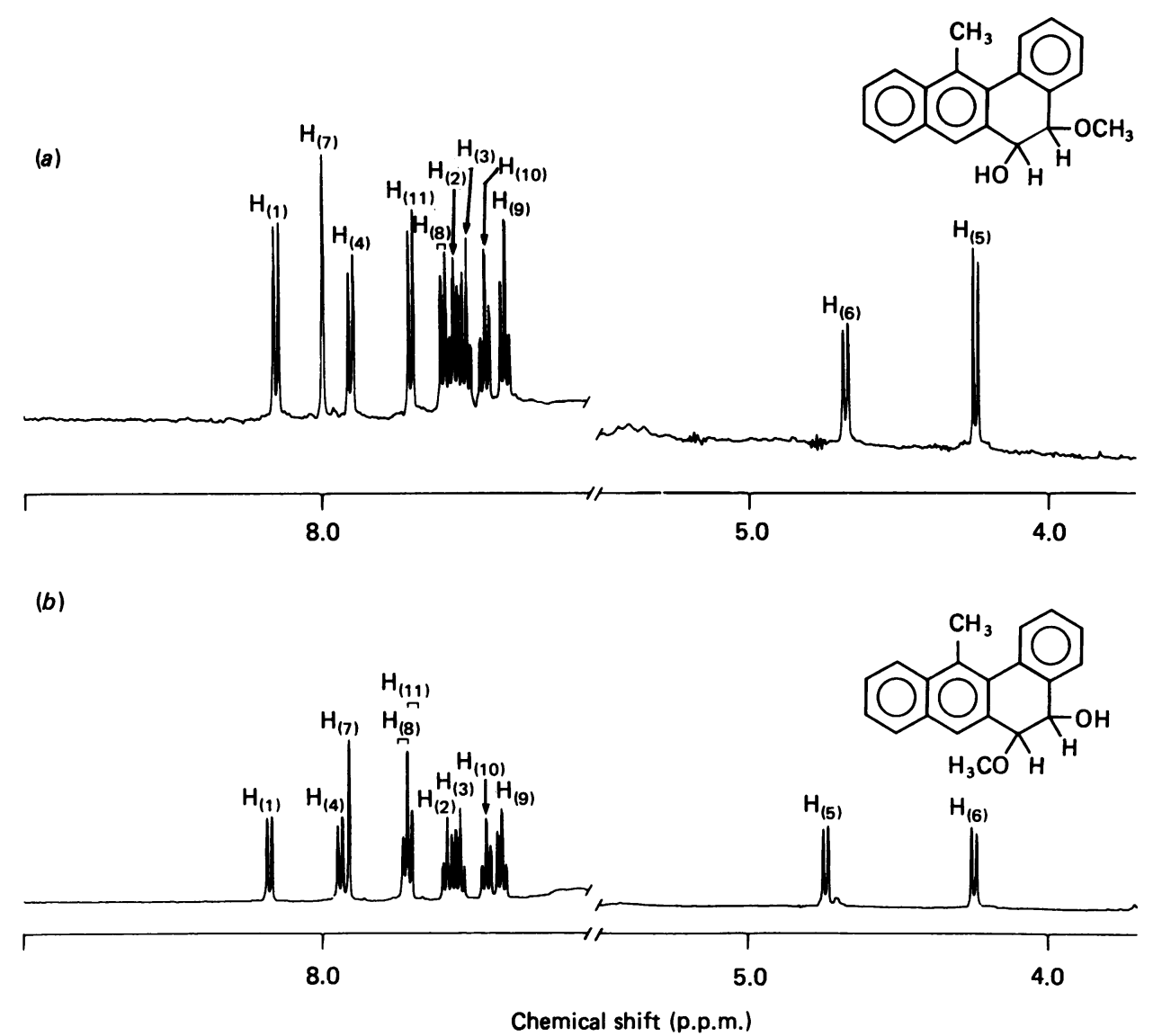

Fig. 8. High-resolution ( $500 \mathrm{MHz})$ n.m.r. spectra of the monomethyl ethers identified as trans-5,6-dihydro-6-hydroxy-5-methoxy12-MBA ( $a$; peak E3 in Fig. 6a) and trans-5,6-dihydro-5-hydroxy-6-methoxy-12-MBA (b; peak E2 in Fig. 6a)

See the text for the assignment of protons and the Experimental section for experimental conditions.

enantiomer formed in the metabolism of 12-MBA by liver microsomes from MC-treated rats has a $5 S, 6 R$ absolute stereochemistry (see Fig. 6b).

\section{Structures of two monomethyl ethers determined by n.m.r. spectroscopy}

Proton-n.m.r. spectra of methoxylation products (peaks E2 and E3 in Fig. 6a) were determined by high-resolution $500 \mathrm{MHz}$ proton-n.m.r. spectroscopy, and the data are shown in Table 2 and Fig. 8. The chemical shifts and coupling constants of protons in 12-MBA and some of its $\mathrm{K}$-region derivatives were determined by extensive homonuclear decouplings and by n.O.e. difference spectra.

The presence of n.O.e. signals upon irradiation at the $\mathrm{C}_{(12)}$-methyl resonance of 12-MBA allowed the identification of $H_{(1)}$ and $H_{(11)}$. The resonance signal of $H_{(1)}$ was assigned to the lower-field doublet ( 8.69 p.p.m.) due to a stronger ring-current effect and van der Waals interactions with protons of the $\mathrm{C}_{(12)}$-methyl group, which was distinguished from that of $\mathrm{H}_{(1)}(8.43$ p.p.m.). Subsequent decouplings of $\mathbf{H}_{(1)}$ and $\mathbf{H}_{(11)}$ helped to establish the resonance signals of $\mathbf{H}_{(2)}$ and $\mathbf{H}_{(10)}$ respectively. The chemical shift of the proton at $\mathrm{C}_{(7)}$ was readily recognized by its apparent singlet at 8.34 p.p.m. The presence of an n.O.e. from $\mathbf{H}_{(7)}$ allowed the assignments of $\mathrm{H}_{(6)}$ (a sharp doublet) and $\mathrm{H}_{(8)}$ (a broad doublet of a doublet). The resonance signal of $\mathrm{H}_{(5)}$ was readily established by homonuclear decoupling of $\mathbf{H}_{(6)}$.
$H_{(4)}$, a doublet of a doublet at 7.92 p.p.m., experienced a stronger ring-current effect, hence a chemical shift occurred at a lower field, than $\mathrm{H}_{(2)}, \mathrm{H}_{(3)}, \mathrm{H}_{(9)}$ and $\mathrm{H}_{(10)}$, which were apparent triplets clustered at 7.59-7.70 p.p.m.

High-resolution $500 \mathrm{MHz}$ proton-n.m.r. spectra of methoxylation products E2 and E3 are shown in Fig. 8. The assignments of aromatic proton resonances were established by extensive homonuclear decouplings, n.O.e. difference spectra, and by comparison with the assigned proton resonances of 12-MBA. In the n.m.r. spectrum of the E2 compound, the singlet at 7.91 p.p.m. is readily assigned to $H_{(7)}$. Upon irradiation of $H_{(7)}$ at 7.91 p.p.m., the resulting n.O.e. difference spectrum allowed the assignments of the carbinol proton $\mathbf{H}_{(6)}$ (4.24 p.p.m.) and the aromatic proton $\mathrm{H}_{(8)}$ (7.72 p.p.m.). The carbinol proton at $\mathrm{C}_{(5)}(4.73$ p.p.m.) was therefore readily assigned. Upon irradiation of the methoxy resonance at 3.65 p.p.m., the n.O.e. difference spectrum confirmed the assignments of $H_{(6)}\left(4.24\right.$ p.p.m.) and $H_{(7)}$ (7.91 p.p.m.). Furthermore, $H_{(1)}\left(8.17\right.$ p.p.m.) and $H_{(11)}$ (7.70 p.p.m.) were found to receive an n.O.e. upon irradiation of the $\mathrm{C}_{(12)}$-methyl protons at 2.93 p.p.m. The remainder of the resonances of compound E2 was assigned by extensive homonuclear decouplings. These results indicate that the methoxy group of compound E2 is at the $C_{(6)}$ position. Similarly, irradiation of $\mathbf{H}_{(7)}$ (singlet at 7.99 p.p.m.) of compound E3 resulted in an n.O.e. difference spectrum that allowed the assignments of the carbinol proton $H_{(6)}$ (4.67 p.p.m.) and the 
aromatic proton $\mathrm{H}_{(8)}$ (7.59 p.p.m.). Assignments of $\mathrm{H}_{(6)}$ facilitated the assignment of the carbinol proton at $\mathrm{C}_{(5)}$ (4.24 p.p.m.). Irradiation of the methoxy resonances at 3.61 p.p.m. resulted in an n.O.e. difference spectrum that confirmed the assignment of $\mathrm{H}_{(5)}$ (4.24 p.p.m.) and also allowed the assignment of $\mathrm{H}_{(4)}$ (7.90 p.p.m.) in compound E3. Irradiation of the $\mathrm{C}_{(12)}$-methyl resonances at 2.91 p.p.m. allowed the assignments of $\mathrm{H}_{(1)}$ (8.15 p.p.m.) and $H_{(11)}$ (7.70 p.p.m.). The remainder of the resonances were assigned by selective homonuclear decouplings and comparison with the n.m.r.-spectral data of 12-MBA. These results indicate that the methoxy group of compound E3 is at the $\mathrm{C}_{(5)}$ position.

Additional evidence further support the above conclusion. A hydroxy group can cause a more downfield shift to a geminal proton (e.g., $\mathrm{H}_{(5)}$ is a geminal proton to the $\mathrm{C}_{(5)}$-hydroxy group) than a methoxy group (Gunther, 1980). The chemical shift of $\mathrm{H}_{(5)}$ (4.73 p.p.m.) of the methoxylation product $\mathrm{E} 2$ is at a lower field than that of $\mathrm{H}_{(5)}(4.24$ p.p.m.) of the methoxylation product E3. These results indicate that a hydroxy group is at $\mathrm{C}_{(5)}$ of compound E2 and a methoxy group is at $C_{(5)}$ of compound $E 3$. The chemical shifts of protons at $C_{(6)}$ of compounds E2 (4.24 p.p.m.) and E3 (4.67 p.p.m.) are also consistent with the structural assignments described above. Coupling constants between the carbinol protons $\left(J_{5,6}\right)$ are both $8.2 \mathrm{~Hz}$, indicating that both compounds E2 2 and E3 are trans isomers and adopt preferentially quasi-diequatorial conformations (Zacharias et al., 1979; Fu et al., 1983).

The results presented above established that methoxylation product E2 is trans-5,6-dihydro-5-hydroxy-6methoxy-12-MBA and that methoxylation product E3 is trans-5,6-dihydro-6-hydroxy-5-methoxy-12-MBA. These conclusions are consistent with the results that the structures of compounds D2 and D3, which are derived by methylation of 12-MBA trans-5,6-dihydrodiol, are identical with those of compounds E2 and E3 respectively (except that D3 and E3 are a pair of enantiomers).

\section{C.d. spectra and conformation of an enantiomeric bis-methyl ether}

A bis-methyl ether was prepared by reaction of 12-MBA $5 S, 6 S$-dihydrodiol with an excess amount of methyl iodide, and its c.d. spectrum is shown in Fig. 6(d). The conformation of K-region trans-dihydrodiol and its derivatives can be determined by the coupling constant between the carbinol protons: quasi-diequatorial with $J_{5,6}=9-11 \mathrm{~Hz}$ and quasi-diaxial with $J_{5,6}=2-4 \mathrm{~Hz}(\mathrm{Fu}$ et al., 1983). The hydroxy groups of 12-MBA trans5,6-dihydrodiol are preferentially in quasi-equatorial positions $\left(J_{5,6}=10.3 \mathrm{~Hz}\right)$ (Fu et al., 1982). When one of the hydroxy groups is methylated, the hydroxy and methoxy groups of the resulting two monomethyl ethers remain preferentially at quasi-equatorial positions $\left(J_{5,6}=8.2 \mathrm{~Hz}\right.$; Table 2$)$. However, when both hydroxy groups of 12-MBA trans-5,6-dihydrodiol are methylated, the methoxy groups in the resulting bis-methyl ether are now preferentially in quasi-axial positions $\left(J_{5,6}=4.7 \mathrm{~Hz}\right.$; Table 2). Similarly to previous observations (Fu \& Yang, 1983; Chiu et al., 1984; Yang \& Fu, 1984a,b), this change in conformation of a K-region dihydrodiol is accompanied by a change in the sign of c.d. Cotton effects in the wavelength region approx. 225-245 nm (Figs. $2 a$ and $6 d)$.

\section{Structures of 5-methoxy-12-MBA and 6-methoxy-12-MBA}

The structures of chemically synthesized 5-methoxy12-MBA and 6-methoxy-12-MBA, which were separated by reversed-phase h.p.l.c., were established by u.v. absorption, mass-spectral and proton-n.m.r.-spectral analyses. Both isomers have essentially identical mass spectra $\left(M^{+}\right.$at $m / z 272$, with base peak at $m / z 229$; electron impact). U.v. absorption spectra (Fig. 7) showed that these two positional isomers differ substantially in their absorption properties. The resonances of protons in each isomer were determined by selective homonuclear decouplings, by n.O.e. difference spectra, and by comparison with the n.m.r.-spectral data of 12-MBA. Comparison of the n.m.r. spectra of 5-methoxy-12-MBA and 12-MBA indicated that the methoxy group caused the peri $\mathrm{H}_{(4)}$ a downfield shift of 0.41 p.p.m. (from 7.92 to 8.33 p.p.m.), and the ortho $\mathrm{H}_{(6)}$ an upfield shift of 0.66 p.p.m. (from 7.77 to 7.11 p.p.m.) (Table 2). Similarly, the methoxy substituent of 6-methoxy-12MBA caused the peri $\mathrm{H}_{(7)}$ a downfield shift (from 8.34 to 8.75 p.p.m.) of 0.41 p.p.m. and the ortho $\mathrm{H}_{(5)}$ an upfield shift (from 7.64 to 7.03 p.p.m.) of 0.61 p.p.m. The direction in the changes and the magnitude of chemical shifts of the peri and ortho protons due to the presence of a methoxy substituent are consistent with results obtained in other compounds (Gunther, 1980; Balani et al., 1985).

\section{DISCUSSION}

Knowledge of the absolute configuration of enantiomeric epoxides and dihydrodiols is essential in the elucidation of the mechanisms of metabolic stereoselective formation and hydration of epoxides, reactions that are catalysed by cytochrome $P-450$ isoenzymes and epoxide hydrolase. In the present study, the absolute configurations of enantiomeric 12-MBA 5,6-epoxide and trans-5,6-dihydrodiol were elucidated by rigorous methods. Consequently, the relationship between c.d. spectra and absolute configurations of enantiomeric 12-MBA 5,6-epoxide and trans-5,6-dihydrodiol are unequivocally established. The c.s.p.-h.p.l.c. method in the separation of enantiomeric 12-MBA 5,6-epoxide and 12-MBA trans-5,6-dihydrodiol is also important in determining the enantiomeric compositions of K-region epoxides and dihydrodiols. Since u.v. and fluorescence detectors are commonly used in the c.s.p.-h.p.l.c. method, the enantiomeric compositions of sub-microgram quantities of an epoxide or a dihydrodiol formed in the metabolism of 12-MBA in an enzyme system can be readily determined. When the enantiomers can be resolved, the c.s.p.-h.p.l.c. method is a more rapid and sensitive method than the analysis of diastereomers obtained by reaction of the enantiomers with an optically active agent (Wainer \& Doyle, 1984).

7,12-DMBA 5,6-epoxide is known to react readily with methanol to form two isomeric monomethyl ethers (Wong et al., 1980), which can be separated by normal-phase h.p.l.c. (Mushtaq et al., 1984; Balani et al., 1985). Unlike 7,12-DMBA 5,6-epoxide, chrysene 5,6epoxide (Weems et al., 1986) and 12-MBA 5,6-epoxide do not react readily with methanol; therefore, sodium methoxide and gentle heating are required to hasten the methoxylation reaction. This reaction results in two 


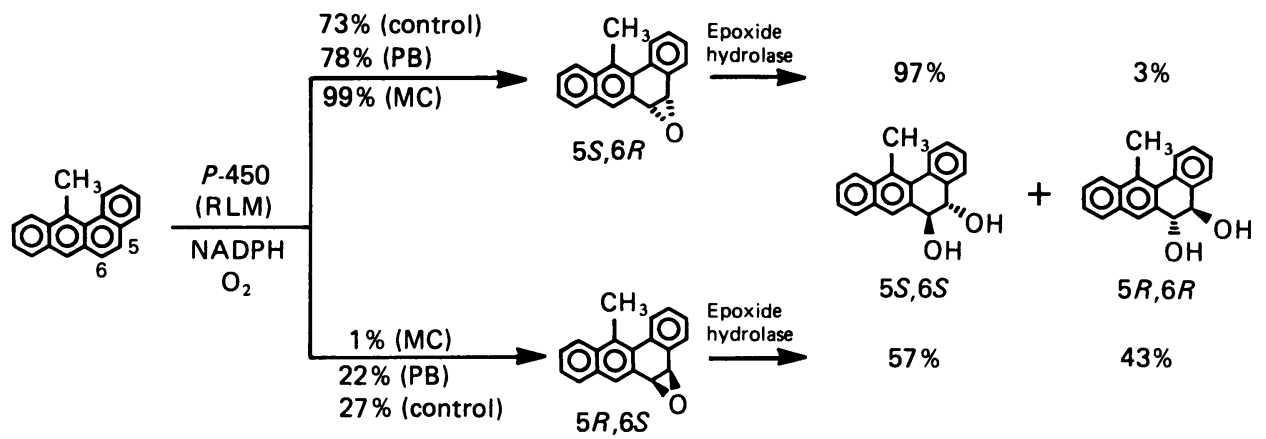

Scheme 1. Stereoselective metabolic formation of 12-MBA 5,6-epoxide enantiomers and their subsequent hydration mechanism by rat liver microsomes

The enantiomeric compositions of the trans-5,6-dihydrodiol formed in the metabolism of 12-MBA by different rat liver microsomal preparations are shown in Table 1. Abbreviation: RLM, rat liver microsomes. Control, PB and MC indicate liver microsomes prepared from untreated, PB-treated and MC-treated male Sprague-Dawley rats respectively.

isomeric monomethyl ethers, which can also be obtained by methylation of trans-5,6-dihydrodiol with methyl iodide. The isomeric monomethyl ethers are separable by normal-phase h.p.l.c. and their enantiomers are separable by c.s.p.-h.p.l.c. Since the positions of the methyl group in the isomeric monomethyl ethers are established by n.m.r. spectroscopy and the absolute configurations of enantiomeric monomethyl ethers are established by comparing their c.d. spectra with an enantiomeric 12MBA trans-5,6-dihydrodiol of known absolute stereochemistry, the absolute configuration of an enantiomeric 12-MBA 5,6-epoxide is readily established. The method described in the present and previous papers (Mushtaq et al., 1984; Balani et al., 1985; Weems et al., 1986) appears to be a general method that is applicable to the determination of absolute configurations of $\mathrm{K}$-region epoxide enantiomers of other PAHs.

The 12-MBA 5,6-epoxide enantiomer less strongly retained by the ionically bonded $(R)-D N B P G$ column is established in this study to be the $5 S, 6 R$ enantiomer. Thus the tentative assignments of the absolute configurations of enantiomeric 12-MBA 5,6-epoxide and 7,12-DMBA 5,6-epoxide in our previous reports (Mushtaq et al., 1984; Weems et al., 1985) were incorrect and these had been indicated in a more recent paper (Weems et al., 1986). The c.d. spectrum of 7,12-DMBA $5 S, 6 R$-epoxide exhibits similar c.d. Cotton effects to those of $12-\mathrm{MBA} 5 S, 6 R$-epoxide.

The 5,6-epoxides formed in the metabolism of 12-MBA by liver microsomes from untreated (control), PB-treated and MC-treated male Sprague-Dawley rats in the presence of TCPO are all enriched in the $5 S, 6 R$ enantiomer. The 5,6-epoxides formed in the metabolism of BA by the same liver microsomal preparations are also enriched in the $5 S, 6 R$ enantiomer (van Bladeren et al., 1982; Yang \& Chiu, 1985; Mushtaq et al., 1986). Without the presence of TCPO in the incubation mixture, the $5 S, 6 S$-dihydrodiol is the major 5,6dihydrodiol enantiomer formed in the K-region metabolism of 12-MBA by all three rat liver microsomal preparations. In contrast, the $5 R, 6 R$-dihydrodiol is the major 5,6-dihydrodiol enantiomer formed in the $K$ region metabolism of $\mathbf{B A}$ by the same rat liver microsomal preparations. These results thus suggest that the $5 S, 6 R$-epoxide of $12-\mathrm{MBA}$ is hydrated predominantly to the $5 S, 6 S$-dihydrodiol enantiomer. This is indeed found to be the case. C.s.p.-h.p.l.c. analyses of hydration products derived from each of the two 12-MBA 5,6-epoxide enantiomers indicate that 12-MBA $5 S, 6 R$ epoxide is hydrated predominantly $(97 \%)$ to the $5 S, 6 S$-dihydrodiol, whereas the 12-MBA $5 R, 6 S$-epoxide is hydrated to a 5,6-dihydrodiol with $(5 S, 6 S) /(5 R, 6 R)$ enantiomer ratio of 57:43. In contrast, BA $5 S, 6 R$-epoxide and BA $5 R, 6 S$-epoxide are hydrated to a trans-5,6-dihydrodiol with $(5 S, 6 S) /(5 R, 6 R)$ enantiomer ratios of 10:90 and 65:35 respectively (Yang \& Chiu, 1985; Armstrong et al., 1981). Epoxide hydrolase activities in different rat liver microsomal preparations have essentially the same regioselective properties in the hydration of K-region epoxide enantiomers (Thakker et al., 1977; Yang \& Chiu, 1985).

Results of the present study reveal the mechanisms in the K-region metabolism of 12-MBA by three rat liver microsomal preparations (Scheme 1). The content and catalytic activity of cytochrome $P-450$ isoenzymes in the livers of rats vary, depending on the chemicals that are used to treat the animals. All three rat liver microsomal preparations preferentially catalyse the formation of the same $5 S, 6 R$ enantiomer. Liver cytochrome $P-450$ isoenzymes in rats pretreated with $\mathrm{PB}$ and $\mathrm{MC}$ have more highly stereoselective properties than that in the untreated rats. Cytochrome $P-448$, the predominant isoenzyme contained in liver microsomes of MC-treated rats, is essentially stereospecific in catalysing the formation of the $5 S, 6 R$-epoxide from both $\mathrm{BA}$ and 12-MBA. It may be noted that BA is a planar molecule, whereas the 1,2,3,4-benzo ring in 12-MBA is at an angle of approx: $21^{\circ}$ relative to the anthracene nucleus (Briant et al., 1985). It is apparent that the non-planarity due to the $\mathrm{C}_{(12)}$-methyl group does not significantly alter the stereoheterotopic interaction between the cytochrome $P-450$ isoenzyme and the 5,6-double bond of the BA molecule. Microsomal epoxide hydrolase apparently has different regioselectivity in the hydration of the $5 S, 6 R$ epoxides derived from the non-planar 12-MBA and the planar BA.

This work was supported in part by U.S. Public Health Service Grant CA29133. The opinions or assertions contained herein are the personal ones of the authors and are not to be construed as official or reflecting the views of the Department of Defense or the Uniformed Services University of the Health 
Sciences or the Food and Drug Administration. The experiments reported herein were conducted according to the principles set forth in the Guide for the Care and Use of Laboratory Animals [Institute of Animal Resources, National Research Council; DHEW Publ. (NIH) (U.S.) no. 78-23 (1978)].

\section{REFERENCES}

Alvares, A. P., Schilling, G., Garbut, A. \& Kuntzman, R. (1970) Biochem. Pharmacol. 19, 1449-1455

Armstrong, R. N., Kedzierski, B., Levin, W. \& Jerina, D. M. (1981) J. Biol. Chem. 256, 4726-4733

Balani, S. K., Yeh, H. J. C., Ryan, D. E., Thomas, P. E., Levin, W. \& Jerina, D. M. (1985) Biochem. Biophys. Res. Commun. 130, 610-616

Boyd, D. R. \& Stubbs, M. E. (1983) J. Am. Chem. Soc. 105, 2554-2559

Bradsher, C. K. (1940) J. Chem. Soc. 62, 1077-1078

Briant, C. E., Jones, D. W. \& Shaw, J. D. (1985) J. Mol. Struct. 130, 167-176

Chiu, P.-L., Fu, P. P. \& Yang, S. K. (1984) Cancer Res. 44, 562-570

Fu, P. P. \& Yang, S. K. (1983) Carcinogenesis 4, 979-984

Fu, P. P., Chou, M. W. \& Yang, S. K. (1982) Biochem. Biophys. Res. Commun. 106, 940-946

Fu, P. P., Evans, F. E., Miller, D. W., Chou, M. W. \& Yang, S. K. (1983) J. Chem. Res. Synops. 158-159

Gunther, H. (1980) NMR Spectroscopy: An Introduction, chapter 4, John Wiley and Sons, New York

Harada, N. \& Nakanishi, K. (1972) Acc. Chem. Res. 5, 257-263

Harada, N., Chen, S.-M. \& Nakanishi, K. (1975) J. Am. Chem. Soc. $97,5345-5352$

Harvey, R. G., Goh, S. H. \& Cortex, C. (1975) J. Am. Chem. Soc. 97, 3468-3479

Jerina, D. M. \& Daly, J. W. (1974) Science 185, 573-581

Lowry, O. H., Rosebrough, N. J., Farr, A. L. \& Randall, R. J. (1951) J. Biol. Chem. 193, 265-275

Lu, A. Y. H. \& West, S. B. (1980) Pharmacol. Rev. 31, 277-295

Received 24 October 1986/31 December 1986; accepted 19 March 1987
Mushtaq, M., Weems, H. B. \& Yang, S. K. (1984) Biochem. Biophys. Res. Commun. 1125, 539-545

Mushtaq, M., Weems, H. B. \& Yang, S. K. (1986) Arch. Biochem. Biophys. 246, 478-487

Sims, P. \& Grover, P. L. (1974) Adv. Cancer Res. 20, 165-274

Thakker, D. R., Yagi, H., Levin, W., Lu, A. Y. H., Conney, A. H. \& Jerina, D. M. (1977) J. Biol. Chem. 252, 6328-6334

Thakker, D. R., Levin, W., Yagi, H., Turujman, S., Kapadia, D., Conney, A. H. \& Jerina, D. M. (1979) Chem.-Biol. Interact. 27, 145-161

van Bladeren, P. J., Armstrong, R. N., Cobb, D., Thakker, D. R., Ryan, D. E., Thomas, P. E., Sharma, N. D., Boyd, D. R., Levin, W. \& Jerina, D. M. (1982) Biochem. Biophys. Res. Commun. 106, 602-609

Wainer, I. W. \& Doyle, T. D. (1984) LC Mag. 2, 89-98

Weems, H. B. \& Yang, S. K. (1982) Anal. Biochem. 125, 156-161

Weems, H. B., Mushtaq, M. \& Yang, S. K. (1985) Anal. Biochem. 148, 328-338

Weems, H. B., Fu, P. P. \& Yang, S. K. (1986) Carcinogenesis 7, 1221-1230

Wong, L. K., Kim, W. H. \& Witiak, D. T. (1980) Anal. Biochem. 101, 34-38

Yang, S. K. \& Chiu, P.-L. (1985) Arch. Biochem. Biophys. 240, 546-552

Yang, S. K. \& Fu, P. P. (1984a) Chem.-Biol. Interact. 49, $71-88$

Yang, S. K. \& Fu, P. P. (1984b) Biochem. J. 223, 775-782

Yang, S. K. \& Li, X.-C. (1984) J. Chromatogr. 291, 265-273

Yang, S. K. \& Weems, H. B. (1984) Anal. Chem. 56, 2658-2662

Yang, S. K., Mushtaq, M., Weems, H. B. \& Fu, P. P. (1984) J. Chromatogr. 316, 569-584

Yang, S. K., Mushtaq, M., Weems, H. B. \& Fu, P. P. (1986a) J. Liq. Chromatogr. 9, 473-492

Yang, S. K., Mushtaq, M., Weems, H. B. \& Fu, P. P. (1986b) Tetrahedron Lett. no. 27, 433-436

Yang, S. K., Mushtaq, M., \& Fu, P. P. (1986c) J. Chromatogr. 371, 195-206

Zacharias, D. E., Glusker, J. P., Fu, P. P. \& Harvey, R. G. (1979) J. Am. Chem. Soc. 101, 4043-4051 